UNIVERSIDADE DE SÃO PAULO

FACULDADE DE MEDICINA DE RIBEIRÃO PRETO

DEPARTAMENTO DE PATOLOGIA E MEDICINA LEGAL

MACRÓFAGOS M1 E M2 E SUA RELAÇÃO COM A ANGIOGÊNESE EM CARCINOMAS ESPINOCELULARES ORAIS AFETANDO PACIENTES JOVENS E IDOSOS 


\section{MACRÓFAGOS M1 E M2 E SUA RELAÇÃO COM A ANGIOGÊNESE EM CARCINOMAS ESPINOCELULARES ORAIS AFETANDO PACIENTES JOVENS E IDOSOS}

VERSÃO CORRIGIDA. A VERSÃO ORIGINAL ENCONTRA-SE DISPONÍVEL TANTO NA BIBLIOTECA DA UNIDADE QUE ALOJA O PROGRAMA, QUANTO NA BIBLIOTECA DIGITAL DE TESES E DISSERTAÇÕES DA USP (BDTD).

Dissertação apresentada ao Programa de Pósgraduação em Patologia da Faculdade de Medicina de Ribeirão Preto da Universidade de São Paulo, como requisito para obtenção do título de mestre em Ciências.

Área de concentração: Patologia

Orientador: Prof. Dr. Jorge Esquiche León

Ribeirão Preto 
AUTORIZO A REPRODUÇÃO E DIVULGAÇÃO TOTAL OU PARCIAL DESTE TRABALHO, POR QUALQUER MEIO CONVENCIONAL OU ELETRÔNICO, PARA FINS DE ESTUDO E PESQUISA, DESDE QUE CITADA A FONTE.

FICHA CATALOGRÁFICA

Teixeira, Lucas Ribeiro

Macrófagos M1 e M2 e sua relação com a angiogênese em carcinomas espinocelulares orais afetando pacientes jovens e idosos. Ribeirão Preto, 2019.

74p: il.; $30 \mathrm{~cm}$

Dissertação de Mestrado, apresentada à Faculdade de Medicina de Ribeirão Preto/USP - Área de concentração: Patologia.

Orientador: León, Jorge Esquiche.

Palavras-chave: carcinoma espinocelular; câncer oral; imunoscenescência; jovens; idosos; macrófagos M1 e M2; angiogênese vascular; angiogênese linfática; imunoistoquímica 


\section{FOLHA DE APROVAÇÃO}

TEIXEIRA, LR. Macrófagos M1 e M2 e sua relação com a angiogênese em carcinomas espinocelulares orais afetando pacientes jovens e idosos.

Dissertação apresentada à Faculdade de Medicina de Ribeirão Preto da Universidade de São Paulo, para a obtenção do Título de Mestre em Ciências.

Área de Concentração: Patologia

Opção: Patologia Experimental

Orientador: Prof. Dr. Jorge Esquiche León

Aprovado em:

\section{BANCA EXAMINADORA}

Prof. Dr.

Instituição:

Julgamento: Assinatura:

Prof. Dr.

Instituição:

Julgamento: Assinatura:

Prof. Dr.

Instituição:

Julgamento: Assinatura: 
Dedico este trabalho aos meus pais, José Arlindo Santos Teixeira e Cristina Pedroso Ribeiro. E à minha querida avó, Dilva Pedroso Ribeiro (in memorian). 
À Universidade de São Paulo, na pessoa do atual Reitor, Prof. Dr. Vahan Agopyan, e do Vice-Reitor, Prof. Dr. Antônio Carlos Hernandes.

À Faculdade de Medicina de Ribeirão Preto da Universidade de São Paulo, na pessoa da Diretora, Profa. Dra. Margareth de Castro, e do Vice-Diretor, Prof. Dr. Rui Alberto Ferriani. Agradeço imensamente por estudar em uma instituição de excelência e que me abriu as portas para um mundo de oportunidades nesta etapa da minha vida.

À Coordenação do Programa de Pós-Graduação em Patologia da Faculdade de Medicina de Ribeirão Preto da Universidade de São Paulo, na pessoa do atual Coordenador, Prof. Dr. Fernando Chahud, e do Vice-Coordenador, Prof. Dr. Alfredo Ribeiro da Silva. Agradeço pela excelente recepção que tive desde o primeiro contato com o Programa e pela disposição em contribuir com minha formação acadêmica.

Ao Prof. Dr. Jorge Esquiche León, pela orientação e pelos conhecimentos transmitidos ao longo desses anos na área de Patologia Oral.

Ao Prof. Dr. Alfredo Ribeiro da Silva, por ter sido tão atencioso e pelo suporte fundamental ao desenvolvimento deste projeto de pesquisa.

Aos funcionários do Departamento de Patologia e Medicina Legal da Faculdade de Medicina de Ribeirão Preto da Universidade de São Paulo, Camila de Luca Zambonini Gimenes, Rodrigo Banzi Miotto e Rosângela Mazzucato C. de Paiva por serem tão prestativos e pelo apoio oferecido durante as atividades do mestrado.

Ao Departamento de Estomatologia, Saúde Coletiva e Odontologia Legal da Faculdade de Odontologia de Ribeirão Preto da Universidade de São Paulo, representado pela atual Chefe, Profa. Dra. Marlivia Gonçalves de Carvalho 
Watanabe, e Vice-Chefe, Prof. Dr, Christiano Oliveira Santos, por permitir a utilização das instalações presentes para o desenvolvimento deste projeto de pesquisa.

Às funcionárias do Laboratório de Oncopatologia do Departamento de Patologia e Medicina Legal - FMRP/USP, Laura Midori Kawasse e Márcia Aparecida Oliva, pela disponibilidade e ajuda na realização de procedimentos de confecção das lâminas de imunoistoquímica, importante para esta pesquisa.

Aos funcionários dos Laboratórios de Histopatologia e Microscopia, do Departamento de Estomatologia, Saúde Coletiva e Odontologia Legal - FORP/USP, Adriana de Mattos Gonçalves da Silva, Gilberto André Silva e Kleber Augusto Loureiro, pelo apoio técnico na utilização dos equipamentos laboratoriais.

Aos meus queridos amigos do G7, Amanda Almeida Martins, Flávia Oliveira da Cunha, Gabriela Queiroz Silva de Souza, Laís Ranieri Makrakis e Thiago Vinicius Cortez, que mesmo após o término da graduação, permanecemos unidos, um ajudando ao outro. Agradeço pela amizade e parceria nos bons e maus momentos desses últimos anos.

Aos meus amigos de pós-graduação, Carla Bento Nelem Colturato, Jessica Luana dos Santos, Rodrigo Neves Silva e Silvia Elena Yacarini Paredes, pela ajuda na realização deste projeto de pesquisa e por tornar o ambiente em que trabalhamos mais alegre e feliz.

À Coordenação de Aperfeiçoamento de Pessoal de Nível Superior (CAPES), pela bolsa concedida nos meses iniciais do mestrado.

À Fundação de Amparo à Pesquisa do Estado de São Paulo (FAPESP), pela bolsa concedida nos meses subsequentes do mestrado (Processo 2017/02502-4). 

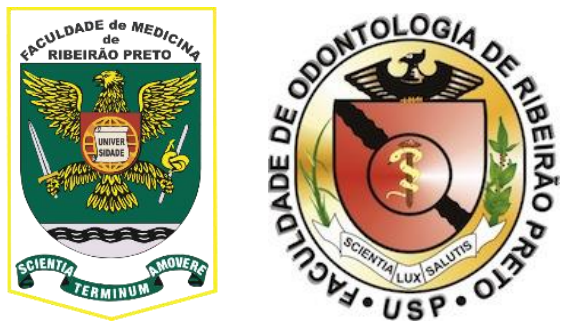

Este trabalho foi desenvolvido no Laboratório de Oncopatologia da Faculdade de Medicina de Ribeirão Preto - USP e nos Laboratórios de Histopatologia e Microscopia da Faculdade de Odontologia de Ribeirão Preto - USP, com apoio financeiro da Fundação de Amparo à Pesquisa do Estado de São Paulo (Processo FAPESP n²017/02502-4 - Bolsa de Mestrado). 


\section{RESUMO}

\section{TEIXEIRA, LR. Macrófagos M1 e M2 e sua relação com a angiogênese em}

carcinomas espinocelulares orais afetando pacientes jovens e idosos. Ribeirão Preto, 2019. 74p. [Dissertação de mestrado]. Faculdade de Medicina de Ribeirão Preto, São Paulo.

O carcinoma espinocelular oral (CECO) corresponde a aproximadamente $95 \%$ das neoplasias malignas que acometem a cavidade oral. Os fatores de risco clássicos incluem o tabagismo e etilismo; no entanto, as disfunções do sistema imune em decorrência do envelhecimento (imunossenescência) na patogênese do CECO são muito pouco estudadas. Análises comparativas vêm sendo feitas para melhor caracterização do perfil de pacientes jovens e idosos acometidos pelo CECO, o qual permanece ainda controverso. Dentre as células imunes, os macrófagos parecem ter um papel fundamental no microambiente tumoral de diversas neoplasias malignas $e$ são classificadas pelos subtipos M1 (com funções pró-inflamatória e anti-tumoral) e M2 (com propriedades anti-inflamatória, pró-angiogênica e pró-tumoral). Vários estudos têm mostrado que os macrófagos associados ao tumor (MATs) exibem um fenótipo M2 no CECO. No entanto, considerando a imunossenescência, não se conhece o perfil detalhado de MATs e seus efeitos na angiogenese no CECO acometendo pacientes jovens e idosos. Assim, este estudo analisou por meio da técnica imunoistoquímica, a frequência e localização de MATs em correlação com a angiogênese, no CECO, afetando diferentes grupos etários. Cinquenta e sete biópsias de CECO divididos em 3 grupos ( $\mathrm{l}:<40$ anos [n=17]; II: 40-65 anos [n=20]; III: $>65$ anos [ $\mathrm{n}=20]$ ) foram selecionados para compor o estudo, sendo classificados morfologicamente seguindo às recomendações da OMS (2017). Os grupos I, II e III foram comparados quanto à imunoexpressão de CD68 e CD163 para análise de MATs e de CD34 (vasos sanguíneos) e D2-40 (vasos linfáticos) para avaliação da densidade microvascular (DMV), área microvascular (AMV) e área vascular total (AVT). A análise imunoistoquímica evidenciou similar expressão de CD68 e CD163 nos três grupos $(p>0,05)$. A avaliação da DMV, AMV e AVT sanguínea e linfática também exibiu padrões similares, com predominância significativa $(p<0.05)$ de vasos sanguíneos, nos três grupos analisados. Não houve correlação significativa quando avaliados marcadores macrofágicos e angiogênicos. Nossos resultados mostram um similar perfil de MATs e angiogênese, sugerindo, ao invés da imunoscenescência, a participação de mecanismos moleculares do microambiente tumoral na manutenção da predominância de macrófagos M2 e vasos sanguíneos no CECO afetando pacientes jovens e idosos.

Palavras-chave: Carcinoma espinocelular; câncer oral; imunoscenescência; jovens; idosos; macrófagos M1 e M2; angiogênese vascular; angiogênese linfática; imunoistoquímica. 


\begin{abstract}
TEIXEIRA, LR. M1 and M2 macrophages and their relation with angiogenesis in oral squamous cell carcinoma affecting young and elderly patients. Ribeirão Preto, 2019. 74p. [Dissertação de mestrado]. Faculdade de Medicina de Ribeirão Preto, São Paulo.
\end{abstract}

Oral squamous cell carcinoma (OSCC) corresponds to approximately $95 \%$ of all cases of oral cavity malignancies. The classic risk factors include smoking and alcoholism; however, immune system dysfunctions due to aging (immunoscencence) in OSCC pathogenesis are poorly studied. Comparative analyzes have been made to better characterize the profile of young and old patients affected by the OSCC, which remains controversial. Among immune cells, macrophages seem to play a fundamental role in the tumor microenvironment of several malignant neoplasms and are classified in M1 (pro-inflammatory and antitumor functions) and M2 (antiinflammatory, pro-angiogenic and pro-tumoral properties) subtypes. Several studies have shown that tumor-associated macrophages (TAMs) exhibit a pro-tumoral M2 phenotype in OSCC. However, considering immunoscencence, the profile of TAMs and their effects on angiogenesis in OSCC affecting young and elderly patients is unknown. Thus, this study analyzed by immunohistochemical technique, the frequency and location of TAMs in correlation with angiogenesis in OSCC affecting different age groups. Fifty-seven biopsies were divided into three groups (I: $<40$ years [n=17]; II: 40-65 years [n=20]; III: $>65$ years [n=20]) and selected to compose this study, being classified morphologically following WHO (2017) recommendations. Groups I, II and III were compared for immunoexpression of CD68 and CD163 for analysis of TAMs, and CD34 (blood vessels) and D2-40 (lymphatic vessels) for evaluation of microvessel density (MVD), microvascular area (MVA) and total vascular area (TVA). Immunohistochemical analysis showed similar expression of CD68 and CD163 in the three groups ( $p>0.05)$. The evaluation of blood and lymphatic MVD, MVA and TVA also showed similar patterns, with a significant predominance $(p<0.05)$ of blood vessels in the three groups analyzed. There was no significant correlation when evaluating macrophage and angiogenic markers. Our results show a similar profile of TAMs and angiogenesis, suggesting, instead of immunoscencence, participation of molecular mechanisms of the tumor microenvironment in the maintenance of M2-polarized macrophages and blood vessels in OSCC affecting young and elderly patients.

Keywords: Squamous cell carcinoma; oral cancer; immunoscencence; young; elderly; M1 and M2 macrophages; vascular angiogenesis; lymphatic angiogenesis; immunohistochemistry. 


\section{LISTA DE TABELAS}

Tabela 1: Anticorpos primários utilizados nas reações de imunoistoquímica

Tabela 2: Dados clinicopatológicos dos casos de CECO incluídos neste estudo, divididos por grupos etários

Tabela 3: Distribuição do grau histopatológico de diferenciação dos casos de CECO selecionados para o estudo

Tabela 4: Estadiamento clínico dos casos selecionados no presente estudo .40

Tabela 5: Distribuição média \pm DP das células imunopositivas para CD68 e CD163 nos compartimentos tumoral (NT) e estromal (ET) no CECO de diferentes grupos analisados 


\section{LISTA DE FIGURAS}

Figura 1: Utilização de tonsila palatina como controle positivo para os anticorpos incluídos na análise imunoistoquímica. O imunomarcador CD68 possui marcação citoplasmática (A: x200; B: x400); e CD163 possui um padrão de marcação em membrana (C: x200; D: x400). O imunomarcador CD34, utilizado para detecção de vasos sanguíneos, exibe marcação no endotélio sanguíneo ( $\mathrm{E}: \mathrm{x200;} \mathrm{F}$ : x400), enquanto D2-40 exibe mostra marcação em endotélio linfático (G: x200; H: x400)

Figura 2: Quantificação de marcadores para macrófagos. $O$ eixo $Y$ indica a média do número total (incluindo ET e NT) de células imunopositivas para CD68 e CD163 por campo de x400 de magnificação. No eixo X, estão indicados os casos de CECO de diferentes grupos etários

Figura 3: Imunoexpressão de macrófagos nos diferentes grupos analisados: presença de células CD68+ (A, x400) e CD163 (B, x400) em pacientes do grupo I; de células CD68+ (C, x400) e CD163+ (D, x400) em pacientes do grupo II e; de células CD68+ (E, x400) e CD163+ (F, x400) em pacientes do grupo III

Figura 4: Dupla marcação imunoistoquímica. Fragmento de tonsila palatina utilizado como controle positivo para imunomarcação dupla, onde a coloração citoplasmática do marcador CD68 (vermelho) foi conferida pelo cromógeno Permanent Red, enquanto a marcação de CD163 (marrom) foi conferida pelo cromógeno DAB (A: x200; B: x400). Caso de CECO representativo (grupo III) exibindo numerosas células CD68+/CD163+ (C: x100; D: x400).

Figura 5: Determinação da DMV sanguínea e linfática no CECO. O eixo $Y$ indica as médias de estruturas vasculares positivas para CD34 e D2-40 na porção estromal, por campo de $\times 400$ de magnificação. No eixo X, estão indicados os casos de CECO de diferentes grupos etários 
Figura 6: Visualização de estruturas vasculares sanguíneas e linfáticas, por meio dos imunomarcadores CD34 e D2-40, respectivamente, no CECO: Presença de vasos sanguíneos $(A, x 400)$ e linfáticos $(B, x 400)$ em pacientes do grupo I; presença de vasos sanguíneos $(C, x 400)$ e linfáticos $(D, x 400)$ em pacientes do grupo II; presença de vasos sanguíneos $(E, x 400)$ e linfáticos em pacientes do grupo III $(F, x 400)$. Note a quantidade significantemente maior de vasos sanguíneos quando comparados aos vasos linfáticos presentes no CECO dos três grupos etários analisados 46

Figura 7: $A M V$ sanguínea e linfática no CECO. $O$ eixo $Y$ indica a área média de estruturas vasculares positivas para CD34 e D2-40 na porção estromal, por campo de x400 de magnificação. No eixo $X$, estão indicados os casos de CECO de diferentes grupos etários 47

Figura 8: AVT sanguínea e linfática no CECO. O eixo $\mathrm{Y}$ indica a média de AVT positivas para CD34 e D2-40 na porção estromal, por campo de x400 de magnificação. No eixo X, estão indicados os casos de CECO de diferentes grupos etários. $\mathbf{4 8}$ 


\section{LISTA DE SIGLAS}

CEC Carcinoma espinocelular

CECO Carcinoma espinocelular oral

INCA Instituto Nacional de Câncer

OMS Organização Mundial de Saúde

IQ Imunoistoquímica

HIS Hibridização in situ

MATs Macrófagos associados ao tumor

TEM Transição epitélio-mesenquima

DMV Densidade microvascular

CVO Carcinoma verrucoso oral

AML Actina de músculo liso

vWf Fator de von-Willebrand

CD68 Cluster of differentiation 68

CD163 Cluster of differentiation 163

CD34 Cluster of differentiation 34

SERPAT Serviço de Patologia

HCRP Hospital das Clínicas de Ribeirão Preto

FMRP Faculdade de Medicina de Ribeirão Preto

SAME Serviço de Arquivo Médico

USP Universidade de São Paulo

H\&E Hematoxilina e eosina

ES Estroma tumoral

NT Ninhos tumorais

DMVS Densidade microvascular sanguínea

DMVL Densidade microvascular linfática

ATV Área total vascular

ATVS Área total vascular sanguínea

ATVL Área total vascular linfática

AMV Área microvascular

AMVS Área microvascular sanguínea

AMVL Área microvascular linfática 
PBS Phosphate buffer solution

DAB 3,3' diaminobenzidina

CECOrof Carcinoma espinocelular de orofaringe

CECLI Carcinoma espinocelular de lábio inferior 


\section{SUMÁRIO}

1. INTRODUÇÃO

1.1. Epidemiologia do câncer de boca.......................................................18

1.2. Carcinoma espinocelular oral (CECO) ...................................................18

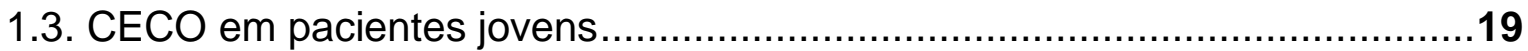

1.4. Imunossenescência no CECO.................................................................21

1.5. Macrófagos associados ao tumor (MAT) no CECO ………………............22

1.6. Influência dos macrófagos na microvasculatura tumoral ...............................24

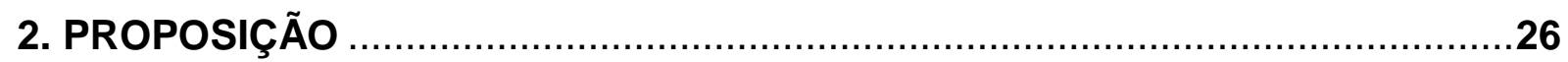

3. MATERIAL E MÉTODOS

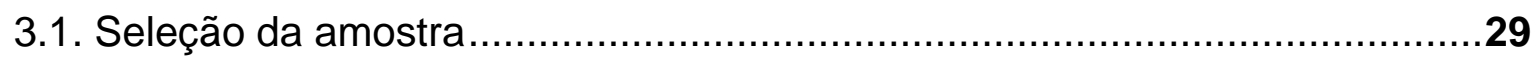

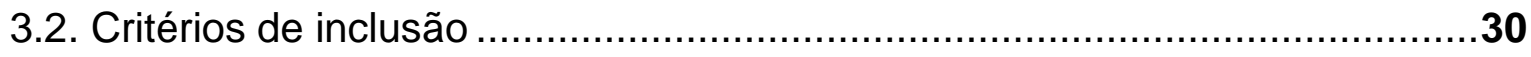

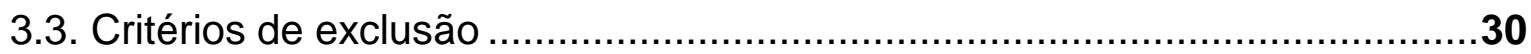

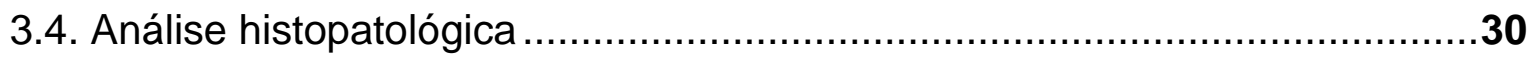

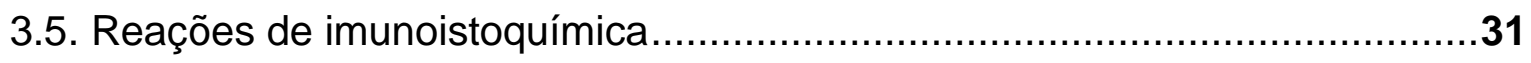

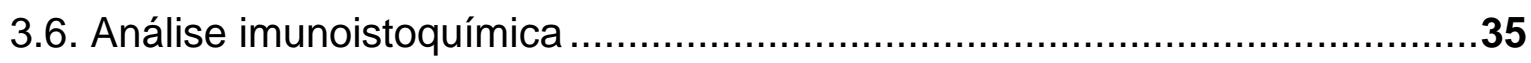

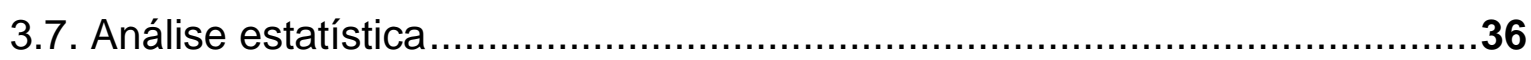

4. RESULTADOS

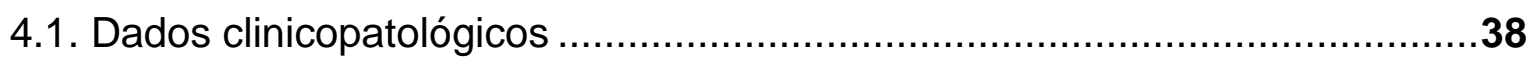

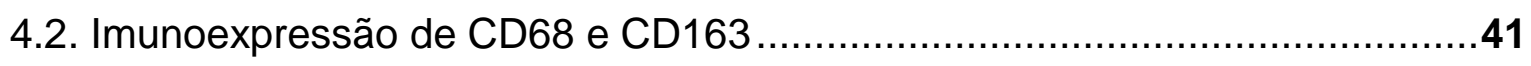

4.3. Imunoexpressão de CD34 e D2-40 .........................................................44

4.4. Correlação entre imunoexpressão de macrófagos e densidade

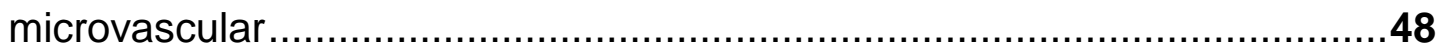

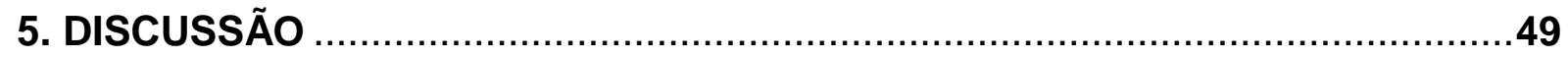

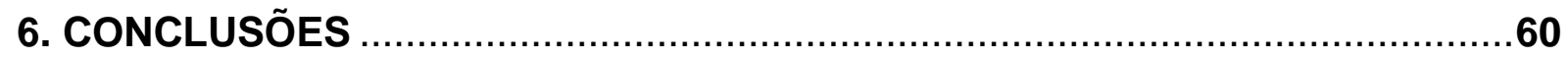

7. REFERÊNCIAS

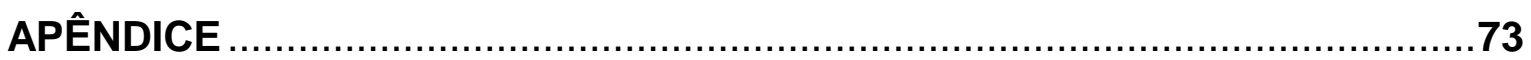




\section{INTRODUÇÃO}

\subsection{Dados epidemiológicos do câncer de boca}

Dados fornecidos pelo Instituto Nacional de Câncer (INCA), órgão vinculado ao Ministério da Saúde, com estimativas de incidência de câncer no Brasil para o biênio 2018-2019, apontaram aproximadamente 600,000 novos casos de câncer, a cada ano. Destes, cerca de 14,700 casos serão em cavidade bucal, estando assim entre os mais frequentes tipos de câncer (5,2\%), apresentando alta incidência em homens, sendo o $5^{\circ}$ tipo de neoplasia maligna mais comum, com 11,200 casos; enquanto em mulheres é tido como o $12^{\circ}$ tipo de câncer mais comum, com 3,500 casos. Para a composição dos cálculos de incidência, foram incluídas as regiões anatômicas dos lábios, cavidade oral, glândulas salivares e orofaringe (INCA, 2018).

Vários estudos têm procurado entender o perfil dos pacientes acometidos pelo câncer de boca quanto ao gênero, idade, hábitos, condições socioeconômicas e culturais. O gênero parece ser um importante fator a ser considerado no câncer de boca do ponto de vista epidemiológico. De modo geral, a frequência se mostra significativamente maior em homens quando comparados às mulheres (Warnakulasariya, 2010; Rikardsen et al., 2014; Bray et al., 2018). No entanto, essa diferença na incidência tem declinado nas últimas décadas (Warnakulasuriya, 2010). Outro fator importante bastante conhecido é a associação do câncer bucal com hábitos nocivos como o fumo e o álcool, porém pacientes não expostos a estes fatores também podem vir a desenvolver a neoplasia, mostrando assim uma provável participação de outros fatores de risco, como susceptibilidade genética e infecção viral (Gupta \& Metgud, 2013).

\subsection{Carcinoma espinocelular oral (CECO)}

Dentre as neoplasias malignas que afetam a cavidade oral, o carcinoma espinocelular (CEC) oral (CECO) é o mais frequente, com aproximadamente $95 \%$ de todos os casos. Segundo a Organização Mundial da Saúde (OMS), o CECO é uma neoplasia maligna com diferenciação escamosa originada do epitélio de revestimento da mucosa oral. Curiosamente, o CECO é abordado de maneira separada daqueles CECs localizados em orofaringe (CECOrof), que compreende o 
terço posterior da língua, tonsila palatina e palato mole (El-Naggar, 2017). Apesar dos avanços acerca do entendimento da biologia tumoral e nas terapias empregadas, a taxa de sobrevida se mantém inalterada nas últimas décadas, com aproximadamente 50\% após 5 anos (Perisanidis et al., 2013; Moro et al., 2018).

Na maioria das vezes, o CECO é diagnosticado em estágios tardios, após o paciente se queixar de sintomatologia dolorosa, apresentando lesões nodulares e/ou ulcerativas (Neville and Day, 2002; Scully e Bagan et al., 2009). Locais como língua, soalho e palato mole exibem uma maior frequência de acometimento, podendo também afetar outras regiões da cavidade oral. Para o diagnóstico, o exame histopatológico deve ser realizado até mesmo para que se possam excluir outras neoplasias malignas como linfomas, sarcomas e metástases originadas de outros órgãos ou tecidos (Silverman, 1988; Rapidis et al., 2009).

Segundo a OMS (2017), após análise histopatológica, o CECO pode ser classificado em pouco, moderadamente ou bem diferenciado. O CEC bem diferenciado mostra configuração tecidual de ilhas tumorais com evidente diferenciação escamosa e pérolas de ceratina. Já o CEC pouco diferenciado, caracteriza-se pelo predomínio de células imaturas, numerosas mitoses típicas e atípicas, bem como ceratinização mínima ou ausente. O CEC moderadamente diferenciado apresenta certo grau de atividade mitótica, pleomorfismo nuclear e ceratinização variável (El-Naggar et al., 2017). O diagnóstico histopatológico do CECO não apresenta dificuldades, no entanto, para fazer o diagnóstico de variantes incomuns do CECO, muitas vezes são necessárias análises complementares como a imunoistoquímica (IQ), hibridização in situ (HIS) e/ou genética molecular. Além disso, o tumor é geralmente avaliado seguindo critérios clínicos. O Comitê Americano de Estadiamento do Câncer estabelece o sistema TNM, tendo como parâmetros: tamanho do tumor primário $(T)$, envolvimento linfonodal regional $(\mathrm{N}) \mathrm{e}$ metástase à distância (M). Tradicionalmente, a classificação do grau histológico e estadiamento de tumores são importantes referências para o prognóstico, bem como para o planejamento de terapias antineoplásicas (Chi et al., 2015).

\subsection{CECO em pacientes jovens}

O acometimento pelo CECO ocorre majoritariamente em pessoas entre a quinta e sétima décadas de vida, com perfil de consumo excessivo de tabaco e 
bebidas alcoólicas por longo período (Llewellyn et al., 2004; Hussein et al., 2017). Apesar de o perfil epidemiológico mostrar altas incidências de CECO na população de meia idade e idosa, estudos publicados nas últimas décadas têm revelado aumentos significativos de acometimento de CECO na população mais jovem, variando entre $4 \%$ a $12 \%$ da população total afetada (lamaroon et al., 2004; Siriwardena et al., 2006; Ribeiro et al., 2009). Hussein e colaboradores (2017) observaram, após revisão sistemática da literatura, aumentos consideráveis nas taxas de incidência de CECO em indivíduos jovens. Outro fato curioso é que, nesse grupo de pacientes, alguns estudos relatam um perfil de indivíduos não tabagistas e/ou não etilistas. Apesar dos achados, ainda são poucos os estudos disponíveis, que ainda contam com diferentes estratégias metodológicas e resultados, dificultando a correta conclusão sobre a caracterização de pacientes jovens afetados pelo CECO (Hussein et al., 2017).

A definição dos grupos etários parece ser um fator importante para a classificação de indivíduos jovens e idosos. No entanto, diferentes faixas etárias são utilizadas nos estudos, tornando difícil uma análise comparativa entre os mesmos. Nos estudos avaliando fatores epidemiológicos, características clínicas, histológicas e moleculares no CECO, o grupo de pacientes jovens pode ser composto por diferentes faixas: menor que 35 anos (Kuriakose et al., 1992; Mallet et al., 2009); menor que 40 anos (Hirota et al., 2008; Benevenuto et al., 2012; Fonseca et al., 2014; Syedmukith et al., 2014; Sun et al., 2015; Frare et al., 2016; Moura et al., 2016; Sgaramella et al., 2016) e; menor que 45 anos (Ribeiro et al., 2009). Em uma publicação recente, Zhang e colaboradores (2017) observaram uma ampla variedade de idade de corte para definição de pacientes jovens (Zhang et al., 2017). Do mesmo modo, é possível encontrar diferentes idades limites para definição de pacientes idosos, como: acima de 40 anos (Hirota et al., 2008; Sun et al., 2015), acima de 50 anos (Benevenuto et al., 2012; Frare et al., 2016; Moura et al., 2016), acima de 60 anos (Kuriakose et al., 1992) e, acima de 65 anos (Sgaramella et al., 2016). Nesse contexto, é possível observar que alguns estudos deixam de analisar faixas entre 40-50 anos.

Os resultados comparativos entre pacientes jovens e idosos afetados pelo CECO têm se mostrado divergentes. Ribeiro e colaboradores (2009) não observaram diferenças quanto ao gênero (predileção por homens), fatores de risco 
(presença de hábitos como tabagismo e etilismo) e grau de diferenciação histológica de tumores encontrados em pacientes jovens quando comparadas às características tradicionais do CECO encontradas na população em geral (Ribeiro et al., 2009). Em contrapartida, outros estudos exibem menor frequência de hábitos de tabagismo e etilismo em pacientes jovens (Kuriakose et al., 1992; Mackenzie et al., 2000; Zhang et al., 2017). Llwellyn e colaboradores (2004) discute que o tempo de exposição ao tabaco e álcool pode estar relacionado com o aumento do risco de CECO, explicando, portanto, um maior risco e frequência de acometimento em pacientes idosos (Llwellyn et al., 2004).

Tendo em vista o melhor entendimento dos mecanismos envolvidos na patogênese do CECO, estudos celulares, moleculares e genéticos com enfoque em pacientes jovens e sua comparação com grupos clássicos de acometimentos têm se mostrado promissores na verificação da hipótese de possíveis diferenças entre faixas etárias. Estudos prévios mostram uma frequente utilização da técnica de imunoistoquímica (IQ) para essa análise comparativa (Kaminagakura et al., 2011; Benevenuto et al., 2012; Fonseca et al., 2014; Moura et al., 2016; Sgaramella et al., 2016; Kaminagakura et al., 2016; Miranda Galvis et al., 2018; Costa et al., 2018), analisando marcadores como p53, Ki-67, p16, ciclina D1, Bcl-2 para estudos de processo celular e atividade proliferativa (Miranda Galvis et al., 2018); actina de músculo liso (AML) para identificação de miofibroblastos/componentes estromais (Fonseca et al., 2014); fator de von-Willebrand e D2-40/podoplanina para reconhecimento de estruturas microvasculares em pacientes jovens e idosos com CECO (Benevenuto et al., 2012; Sgaramella et al., 2016; Moura et al., 2016).

\subsection{Imunossenescência no CECO}

Discutindo a questão da idade, a imunossenescência é amplamente estudada; porém, poucos dados podem ser verificados na sua relação com a imunologia do câncer. Especificamente, até o momento, não há estudos avaliando a relação entre a imunossenescência e o CECO. Imunossenescência é um termo que se refere a um estado de alterações imunológicas relacionadas com 0 envelhecimento cronológico, a qual contribui para o aumento da suscetibilidade a infecções (virais e bacterianas), desordens autoimunes e ao câncer, refletindo em 
uma mortalidade elevada em pacientes idosos (Sebastían et al., 2005). O processo de envelhecimento afeta as imunidades inata e adaptativa, com a diminuição da capacidade de renovação do sistema imunológico com a idade devido a remodelação do organismo. Uma ampla gama de células imunes pode sofrer influências do envelhecimento do organismo: neutrófilos, linfócitos B e T, células dendríticas, plasmócitos e macrófagos (Phelouzat et al., 1996; Sebastian et al., 2005; Weyand \& Goronzy, 2016). O entendimento dos fatores envolvidos na imunossenescencia permanece com poucos esclarecimentos, dado à complexidade multifatorial do sistema imune, considerando as alterações celulares, ambientais ou ambas (Caruso et al., 2009).

Uma das principais funções do sistema imunológico é eliminar células malignas, efetuada por dois mecanismos de defesa que interagem intimamente (imunidade inata e adaptativa), um sistema dinâmico altamente dependente de regeneração das células precursoras hematopoiéticas, e seriamente influenciado pelos os efeitos do envelhecimento imunológico. A compreensão das mudanças no sistema imune em pacientes mais velhos vem sendo requerida visando uma melhor abordagem deste grupo de pacientes acometidos pelo câncer (Fulop et al. 2013).

\subsection{Macrófagos associados ao tumor (MAT) no CECO}

As células do sistema imune compreendem uma parte do chamado microambiente tumoral, caracterizado por um ambiente complexo, onde as células neoplásicas interagem com as células estromais, por meio de sinalizadores químicos. Os mecanismos dessa interação permanecem sem um entendimento claro (Hanahan \& Coussens, 2012). No entanto, a expressão de determinadas citocinas por células tumorais no microambiente tumoral pode direcionar a função das células imunes envolvidas nesse microambiente (linfócitos, células dendríticas e macrófagos), de modo a favorecer um comportamento biológico tumoral mais agressivo, refletindo diretamente em fatores prognósticos (Lippitz, 2013).

Dentre as células não cancerosas envolvidas no microambiente tumoral, os macrófagos (macrófagos associados ao tumor - MATs) tem exibido importante papel no desenvolvimento do CECO. As interações entre células tumorais e macrófagos tem sido cada vez mais discutida (Petruzzi et al., 2017; Alves et al., 2018; Evrard et 
al., 2019) e o entendimento sobre a presença e tipificação dessas células parece ser essencial para uma melhor compreensão da etiopatogenia do CECO. Os macrófagos possuem uma grande plasticidade e inúmeras funções na resposta imune inata (Gordon \& Taylor, 2005; Coffelt et al., 2009), regulada de acordo com o estímulo recebido. Estas células são reconhecidas sob duas polarizações: macrófagos M1 (ativação clássica) e M2 (ativação alternativa). Os macrófagos M1 são estimulados a partir de liberação de interferon-gama (IFN-ү), microorganismos e seus produtos como os lipopolissacarideos (LPS) que promove a liberação de mediadores pró-inflamatórios como IL-1, IL-6 e IFN-y por estas células. São importantes células imunes efetoras, que, por meio de liberação de espécies de oxigênio reativas, atuam na destruição do agente patogênico. Sua ativação também está relacionada a um importante papel antitumoral (Petruzzi et al., 2017; Alves et al., 2018). Já ativação dos macrófagos M2 está intimamente ligada com a liberação de IL-4, IL-8, e IL-10 pelas células tumorais, possuindo propriedades antiinflamatórias, pró-angiogênicas e pró-tumorais, influenciando negativamente no prognóstico de neoplasias malignas (Ruffel et al., 2012; Petruzzi et al., 2017; Alves et al., 2018). A identificação destas subpopulações de macrófagos é feita a partir de análises moleculares, como a IQ (Weber et al., 2016; Alves et al., 2018). Na literatura, uma ampla variedade de marcadores para reconhecimento de macrófagos no CECO, avaliando células CD68+ (Liu et al., 2008; Lu et al., 2010; Fujii et al., 2012; He et al., 2014; Ni et al., 2015; Hu et al., 2016; Weber et al., 2016; Fang et al., 2017; Yamagata et al., 2017), células CD163+ (Fujii et al., 2012; Wang et al., 2014; He et al., 2014; Balermpas et al., 2014; Matsuoka et al., 2014; Weber et al., 2016; Hu et al., 2016; Yamagata et al., 2017), células CD11c+ (Weber et al., 2016); células CD11b+ (Balermpas et al., 2014), células MRC1+ (Weber et al., 2016) e células CD204+ (Yamagata et al., 2017). No CEC de lábio, o marcador HLA-DR também foi utilizado em investigação de população de macrófagos (Lucio et al., 2016). Em uma revisão sistemática, Alves e colaboradores (2018) observaram que em estudos avaliando a infiltração e polarização de macrófagos no CECO, o marcador CD68 é o mais utilizado para o reconhecimento de macrófagos, seguido do imunomarcador CD163, (Alves et al., 2018). O CD68 (cluster of differentiation 68) é uma glicoproteína transmembrana do tipo I, expressa em monócitos e macrófagos teciduais (Holness \& Simmons, 1993, Iqbal et al., 2014). O CD163 (cluster of 
differentiation 163) é uma glicoproteína de superfície celular expressa exclusivamente em células de linhagem monocíticas, sendo altamente expressos em macrófagos residentes em tecidos (Fabriek et al., 2009, Maniecki et al., 2011). O perfil imunofenotípico de macrófagos $\mathrm{M} 1$ é frequentemente identificado pela positividade por HLA-DR, CD11c e CD80 (Mori et al., 2011; Lucio et al., 2016; Alves et al., 2018), enquanto o fenótipo M2 pode ser identificado pelos marcadores CD163, CD11b, CD204, CD206 e MRC-1 (Weber et al., 2016; Yamagata et al., 2017; Alves et al., 2018). A diversidade metodológica quanto ao uso de diferentes marcadores imunoistoquímicos também têm gerado resultados divergentes, o que dificulta uma conclusão sobre o papel deste importante componente do sistema imune. No entanto, sabe-se que a presença dos MATs tem sido associada com o prognóstico e desfecho clínico de indivíduos com CECO. Werhan e colaboradores (2014) mostraram que o comportamento biológico do CECO está associado com a alteração da polarização de macrófagos em gânglios linfáticos afetados, do tipo M1 (antitumoral) para o tipo M2 (indutor de tumor) (Werhan et al., 2014). Hu e colaboradores (2016) observaram que os MATs poderiam promover a transição epitélio-mesênquima (TEM) de células neoplásicas, favorecendo a progressão do CECO (Hu et al., 2016). Interessantemente, não há estudos comparativos quanto à infiltração e caracterização imunofenotipica das diversas células do sistema imune envolvidas no microambiente tumoral, como linfócitos, células dendríticas, e, especificamente, quanto à expressão de macrófagos em pacientes jovens e idosos com CECO.

\subsection{Influência dos macrófagos na microvasculatura tumoral}

Como relatado anteriormente, os macrófagos possuem mecanismos de estímulo vascular sanguíneo (angiogênese) e linfático (linfangiogênese). A angiogênese se refere à formação de um vaso a partir de um já pré-existente. No câncer, a angiogênese tem sido amplamente estudada de modo a verificar a sua relação com o comportamento do tumor, como invasão aos tecidos adjacentes, metástase linfonodal e à distância, de interesse prognóstico (Weidner, 1993; Shivamallapa et al., 2011). Muitos estudos comumente associam a relação entre angiogênese e o desenvolvimento/progressão de neoplasias malignas intraorais 
como o CECO, além de lesões com potencial de malignização (Tipoe et al., 1996; Shivamallapa et al., 2011; Chawla et al., 2015). Mediadores químicos lançados no microambiente tumoral por células tumorais e células estromais (como macrófagos e mastócitos) estão envolvidos no processo de angiogênese em neoplasias malignas. Apesar disso, resultados contrastantes dificultam o entendimento sobre seu papel tumoral no câncer de boca (Shivamallapa et al., 2011).

Além de importante papel na formação vascular sanguínea, evidências recentes mostram que os macrófagos também possuem capacidade de regulação da linfangiogênese, tanto no processo inflamatório quanto em neoplasias (Ran \& Montgomery, 2012; Riabov et al., 2014; Corliss et al., 2016). O desenvolvimento de vasos linfáticos no microambiente tumoral cria uma nova rota para a disseminação tumoral, podendo ocasionar em metástase linfonodal regional e à distância em muitos tipos de câncer. Diferente dos melanomas cutâneos, a formação linfática nos carcinomas se dá na porção estromal dos tumores (Corliss et al., 2016; Farnsworth et al., 2018; Ma et al., 2018).

Poucos estudos têm procurado entender a frequência/polarização de macrófagos e o índice angiogênico (El-Rouby, 2010; Bôas et al., 2013; Udeabor et al., 2017; Chawla et al., 2017) e linfangiogênico (Yamagata et al., 2017) no CECO, motivo pelo qual a clara relação entre estes componentes tumorais se mantenha pouco compreendida.

Considerando que o processo de envelhecimento do organismo atua sobre os componentes do sistema imune (que inclui os macrófagos) e no processo de remodelação dos tecidos (que inclui a angiogênese), há grande necessidade de elucidar os efeitos da imunossenescência na tipificação destas populações macrofágicas (M1 e M2) e na microvasculatura do CECO. Assim, os resultados deste estudo, a qual visa verificar a relação dessas variáveis (macrófagos M1 e M2, angiogênese e imunossenescência), pode fornecer valiosa informação acerca dos mecanismos etiopatogenéticos no CECO afetando pacientes jovens e idosos, visando à adoção de abordagens imunoterapêuticas, com impacto no prognóstico. 


\section{PROPOSIÇÃO}




\section{PROPOSIÇÃO}

\subsection{Objetivo geral}

Este trabalho teve como objetivo avaliar a presença, quantidade e polarização de MATs em correlação com a angiogenese e linfangiogênese, em biópsias de CECO afetando pacientes com $<40$ anos, entre 40-65 anos e $>65$ anos, por meio de análise IQ, visando elucidar os efeitos da imunossenescência na polarização de macrófagos e na modulação da angiogênese, no CECO.

\subsection{Objetivos específicos}

- Avaliar a frequência e localização do marcador CD68 no CECO e estabelecer correlações clinicopatológicas;

- Avaliar a frequência e localização do marcador CD163 no CECO e estabelecer correlações clinicopatológicas;

- Avaliar a frequência e localização do marcador angiogênico CD34 no CECO e estabelecer correlações clinicopatológicas;

- Avaliar a frequência e localização do marcador linfangiogênico D2-40 no CECO e estabelecer correlações clinicopatológicas;

- Avaliar a correlação dos marcadores macrofágicos e angiogênicos no CECO. 


\section{MATERIAL E MÉTODOS}




\section{MATERIAL E MÉTODOS}

O presente estudo, o qual faz parte do projeto de pesquisa intitulado "Estudo clinicopatológico, imunoistoquímico, hibridização in situ e genética molecular em carcinomas espinocelulares da região de cabeça e pescoço" foi apreciado e aprovado pelo Comitê de Ética em Pesquisa do Hospital das Clínicas de Ribeirão Preto da Faculdade de Medicina de Ribeirão Preto - Universidade de São Paulo (CAEE: 60786216.8.0000.5440) (Apêndice 1).

\subsection{Seleção da amostra}

Realizamos um estudo retrospectivo e obtivemos 57 casos de CECO, divididos em três grupos (I: $<40$ anos [n=17]; II: 40-65 anos [n=20]; III: >65 anos $[n=20]$ ), disponibilizada pelo Serviço de Patologia (SERPAT) do Hospital das Clínicas de Ribeirão Preto da Faculdade de Medicina de Ribeirão Preto Universidade de São Paulo (HCRP-FMRP-USP). Em todos os casos selecionados, o procedimento clínico para obtenção dos tecidos foi à remoção parcial da lesão (biópsia incisional) ou remoção cirúrgica da lesão (peça cirúrgica) para fins diagnósticos e terapêuticos, respectivamente. Para a seleção, consideramos importante a diferenciação entre lesões de cavidade oral e orofaringe, uma vez que evidências científicas mostram fatores de risco, comportamento biológico e fatores prognósticos distintos em CECs nessas localizações. Assim, seguindo as recomendações da OMS (2017), localizações como soalho, palato duro, trígono retromolar, tecido gengival e os dois terços anteriores da língua foram aceitos para compor o presente estudo. Já as regiões de palato mole, tonsila palatina e base de língua (orofaringe) não foram consideradas para o estudo (El-Naggar et al., 2017). Após a seleção, os blocos fixados em parafina foram disponibilizados pelo Laboratório de Anatomia Patológica, pertencente à mesma instituição. A obtenção das informações de cada caso analisado foi obtida por meio de análise dos registros médicos disponibilizados pelo Serviço de Arquivo Médico (SAME-HCRP-FMRPUSP), através de prontuários físicos e digitais, avaliando fichas clínicas de exames, acompanhamentos, laudos histopatológicos e imaginológicos. 


\subsection{Critérios de inclusão}

Foram incluídos no presente estudo:

- Os casos de CECO que apresentaram informações clínicas completas, tais como gênero, idade, localização e tipo de lesão;

- Os casos de CECO com disponibilidade de tecido em parafina, suficiente para análise e confirmação histopatológica bem como para novos cortes histológicos, exigidos para as reações de imunoistoquímica;

- $\quad$ Os casos de CECO, cuja análise histopatológica mostrasse infiltração evidente do tecido conectivo subjacente por células epiteliais neoplásicas.

\subsection{Critérios de exclusão}

Foram excluídos no presente estudo:

- Qualquer caso com alterações na fixação e/ou processamento do tecido;

- Qualquer caso com história prévia de radioterapia e/ou quimioterapia ou qualquer outro tratamento antes do procedimento cirúrgico;

- $\quad$ Casos em que a lesão representava recorrência tumoral;

- $\quad$ Casos em que o paciente possuía outras lesões malignas em outros locais, portadores de doenças autoimunes ou portador do vírus da imunodeficiência humana (HIV).

\subsection{Análise histopatológica}

Os blocos de tecido fixados em formol e embebidos em parafina foram seccionados com $5 \mu \mathrm{m}$ de espessura e corados com hematoxilina-eosina (H\&E), utilizados para descrição morfológica e confirmação do diagnóstico dos casos 
selecionados. Para isso, os espécimes foram avaliados através de um microscópio de luz (Leica DM1000, Leica Microsystems CMS GmBH, Wetzlar, Alemanha).

\subsubsection{Estágio Morfológico e classificação}

O grau de diferenciação celular no CECO foi estabelecido de acordo com os critérios propostos pela classificação dos tumores elaborada pela OMS (El-Naggar et al., 2017). Assim, os casos incluídos na amostra foram classificados em: grau I (bem diferenciado), grau II (moderadamente diferenciado) e grau III (pobremente diferenciado).

\subsection{Reações de imunoistoquímica}

\subsubsection{Protocolo imunoistoquímico}

Todos os espécimes foram fixados em formol a $10 \%$ por 24 horas em temperatura ambiente, embebidos em parafina e cortados em secções paralelas consecutivas com $3 \mu \mathrm{m}$ de espessura. Para os procedimentos de IQ, os cortes histológicos foram colocados sobre lâminas revestidas de organo-silano (SigmaAldrich, St Louis, MO, EUA). A desparafinização foi realizada utilizando solução de xilol e a hidratação dos tecidos se deu através da passagem em solução de etanol com concentrações seriadas. A recuperação antigênica para os imunomarcadores CD68, CD163 (macrófagos), CD34 (vasos sanguíneos) e D2-40 (vasos linfáticos) foi feita por imersão dos cortes em solução buffer pH ácido (Citrate Buffer, Target Retrieval Solution, pH6). A inativação da peroxidase endógena tecidual foi executada utilizando peróxido de hidrogênio $\left(\mathrm{H}_{2} \mathrm{O}_{2}\right)$ a $0,5 \%$, por 10 minutos. Em seguida, os cortes foram imersos em PBS (phosphate buffer solution, $\mathrm{pH} 7,4$ ) para serem lavados e preparados para aplicação dos anticorpos primários CD68, CD163, CD34 e D2-40 (ver tabela 1). Após aplicação dos anticorpos primários, as lâminas foram encubadas em câmara úmida, a $4^{\circ} \mathrm{C}$, por 16 horas ("overnight"). 
Tabela 1: Anticorpos primários utilizados nas reações de imunoistoquímica.

\begin{tabular}{ccccc}
\hline Anticorpo & Fornecedor & Tipo & Clone & Diluição \\
\hline CD68 & Dako Cytomation & Monoclonal - camundongo & KP1 & $1: 3.000$ \\
CD163 & Leica Novocastra & Monoclonal - camundongo & 10 D6 & $1: 500$ \\
CD34 & Leica Novocastra & Monoclonal - camundongo & QBEnd/10 & $1: 500$ \\
Podoplanina & Dako Cytomation & Monoclonal - camundongo & D2-40 & $1: 500$ \\
\hline
\end{tabular}

$\mathrm{Na}$ segunda etapa do protocolo, foi realizado o descarte dos respectivos anticorpos primários utilizados e lavagem das lâminas solução de tampão de lavagem (Wash Buffer, Dako North America, Inc. Carpinteria, CA, EUA) acrescida de água destilada. Em seguida, foi aplicado 0 anticorpo secundário biotinilado (LSAB+System-HRP, Dako North America, Inc. Carpinteria, CA, EUA) e deixadas encubadas em temperatura ambiente por 30 minutos, cada passo. Após, executamos a aplicação do cromógeno (Liquid DAB+Substrate Cromogen System, Dako North America, Inc. CA, EUA) por 3-5 minutos em temperatura ambiente. Finalmente, os tecidos passaram por diversas lavagens em água corrente e água destilada, seguindo por contra-coloração com Hematoxilina de Carazzi previamente filtrada (por 5 minutos) e posterior desidratação dos tecidos por imersão em solução de álcool com concentrações crescentes, imersão em xilol de diafanização e montagem das lâminas com Enthelan®. Fragmentos de tonsila palatina foram utilizados como controle positivo para os anticorpos utilizados (ver figura 1).

Para a realização de reações de dupla marcação imunoistoquímica visando avaliação fenotípica dos MATs, foi estabelecido o seguinte protocolo laboratorial: os cortes histológicos foram colocados sobre lâminas revestidas de organo-silano (SigmaAldrich, St Louis, MO, EUA). A desparafinização foi realizada utilizando solução de xilol e a hidratação dos tecidos se deu através da passagem em solução de etanol com concentrações seriadas. A recuperação antigênica para os imunomarcadores CD68 e CD163 foi feita por imersão dos cortes em solução buffer pH ácido (Citrate Buffer, Target Retrieval Solution, pH6). Em seguida, os passos foram realizados seguindo às informações do fabricante do kit específico para este tipo de procedimento (EnVision TM GI2 Doublestain System, Rabbit/Mouse DAB+/Permanent Red, Dako Denmark A/S, Glostrup, Dinamarca), a saber: 1) bloqueio da Peroxidase Endógena (Dual Endogenous Enzyme Block), por 5 minutos; 
2) encubação do anticorpo primário CD163 em temperatura ambiente, por 1 hora; 3) aplicação do polímero (Polymer/HRP), por 30 minutos; 4) aplicação do cromógeno DAB (DAB+Cromogen/ DAB+ Substrate Buffer), por 15 minutos; 5) aplicação da solução Doublestain Block, por 3 minutos; 6) encubação do anticorpo primário CD68, por 1 hora; 7) aplicação do Rabbit/Mouse (Link), por 10 minutos; 8) aplicação do polímero (Polymer/AP), por 30 minutos; 9) aplicação do cromógeno Red (Permanent Red Cromogen/ Permanent Red Substrate Buffer), por 15 minutos; 10) lavagem em água corrente e água destilada; 11) contra-coloração com Hematoxilina de Carazzi, por 5 minutos; 12) montagem das lâminas com Glycergel Mouting Medium (Dako North America, Inc. Carpinteria, EUA). 


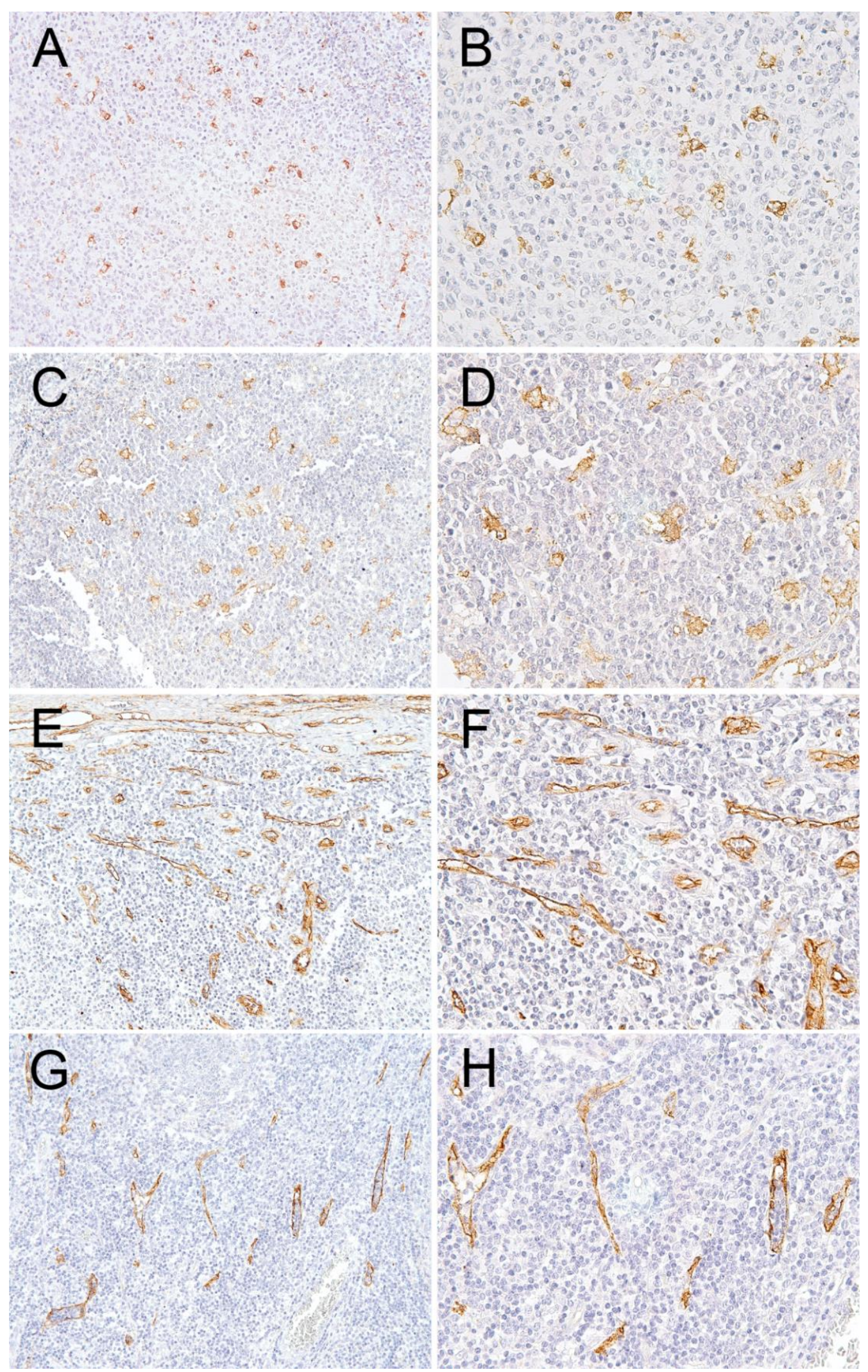

Figura 1: Utilização de tonsila palatina como controle positivo para os anticorpos incluídos na análise imunoistoquímica. O imunomarcador CD68 possui marcação citoplasmática (A: x200; B: x400); e CD163 possui um padrão de marcação em membrana (C: x200; D: x400). O imunomarcador para avaliar vasos sanguíneos CD34, exibe marcação no endotélio sanguíneo (E: x200; F: x400), enquanto D2-40 exibe marcação em endotélio linfático (G: x200; H: x400). 


\subsection{Análise imunoistoquímica}

A imunoexpressão dos anticorpos estudados foi avaliada utilizando-se representação de imagem por meio de um sistema computadorizado, constituído por microscópio de luz (Leica DM500), adaptado a uma câmera de alta resolução (Leica IC50) e monitor de vídeo colorido.

\subsubsection{Avaliação da infiltração de macrófagos}

$\mathrm{Na}$ imunoistoquímica convencional, o reconhecimento dos macrófagos foi confirmado pela contagem de células positivas para CD68 e CD163 que apresentassem coloração acastanhada, conferida pelo cromógeno DAB. Na dupla marcação imunoistoquímica, células mostrando positividade simultânea dos marcadores CD68 (coloração avermelhada conferida pelo cromógeno Permanent Red) e CD163 (coloração acastanhada conferida pelo cromógeno DAB) foram definidas como macrófagos exibindo fenótipo M2. Após análise de todo o tecido disponível para cada caso em aumento de x100, foram selecionados 10 campos microscópicos, incluindo estroma tumoral (ET) e ninhos tumorais (NT), com maior densidade de imunomarcação ("hotspots") para registro fotográfico através do software Leica IM50 Imagem Managem, em aumento de x400.

\subsubsection{Determinação da densidade microvascular sanguínea e linfática}

Os vasos sanguíneos e linfáticos foram observados pela imunopositividade dos marcadores CD34 e D2-40, respectivamente. As áreas tumorais foram observadas por microscópio de luz (Leica DM500, Leica Microsystems, Wetzlar, Alemanha) em baixa magnificação (x100). As 10 (dez) áreas com maior quantidade de vasos corados por CD34 e D2-40 foram selecionadas para registro em alto poder de magnificação (x400). Para determinação da densidade microvascular sanguínea (DMVS) e linfática (DMVL), utilizamos o método descrito por Weidner et al. (1991), que também tem sido utilizado em vários outros estudos recentes (Gadbail et al., 2011, Lima et al., 2011; Sánchez-Romero et al., 2017). Assim, o lúmen dos vasos, embora presente em porção considerável dos vasos imunocorados, não foi 
requerido para a definição de estrutura vascular, assim como a presença de hemácias no caso da análise de vasos CD34 positivos.

Após o registro dos campos para cada caso, realizamos, manualmente, a contagem dos vasos que mostraram imunopositividade para os anticorpos CD34 e D2-40, utilizando o software Image J (National Institutes of Health, Bethesda, MD), além da determinação da área (em micrometros quadrados) de cada estrutura microvascular utilizando o software Leica QWin (Leica Microsystems, Cambridge, United Kingdom). A área microvascular (AMV) foi definida como área das células endoteliais e lúmen. Além disso, foi calculada a área vascular total (AVT), definido como o resultado da soma de cada estrutura vascular presente em um campo de x400 registrado.

\subsection{Análise estatística}

Os dados foram analisados usando o programa estatístico GraphPad Prism, versão 6.0 (La Jolla, Estados Unidos da América). Dados qualitativos foram descritos pelas frequências absolutas e relativas. A estatística descritiva de dados quantitativos incluiu a obtenção de médias e desvio padrão. A expressão dos imunomarcadores foi comparada entre os grupos utilizando o teste ANOVA Oneway, o teste $T$ de Student ou teste de Mann-Whitney. Já a correlação entre os marcadores macrofágicos (CD68 e CD163) e vasculares (CD34 e D2-40) foram analisados por meio do coeficiente de correlação de Pearson ou Spearman. Em todas as análises, o valor- $p<0.05$ foi considerado como diferença significante. 


\section{RESULTADOS}




\section{RESULTADOS}

\subsection{Dados clinicopatológicos}

Os dados clinicopatológicos da amostra estudada evidenciou predominância do sexo masculino (49 homens, 8 mulheres) e maioria de raça leucoderma, em todos os grupos analisados. A média de idade dos pacientes do grupo I (jovens) foi de 35,2 anos, variando de 26 a 38 anos. A média de idade para o grupo II (pacientes adultos) foi de 54,6 anos, variando de 43 a 60 anos. No grupo III (idosos), a média de idade foi de 70,5 anos, variando de 66 a 83 anos. Hábitos como tabagismo e etilismo foram observados em alta frequência nos três grupos, no entanto, sem apresentar diferenças significantes entre eles. Com relação à localização do tumor primário, a língua foi a estrutura anatômica mais acometida em todos os grupos, seguida pelo soalho (ver tabela 2). 
Tabela 2: Dados clinicopatológicos dos casos de CECO incluídos neste estudo, divididos por grupos etários.

Características $\quad$ Grupo I $(n=17) \quad$ Grupo II $(n=20) \quad$ Grupo III $(n=20)$

Gênero

$\begin{array}{clll}\text { Masculino } & 14(82,35 \%) & 18(90,00 \%) & 17(85,00 \%) \\ \text { Feminino } & 03(17,65 \%) & 02(10,00 \%) & 03(15,00 \%)\end{array}$

Raça

$\begin{array}{clll}\text { Leucoderma } & 14(82,35 \%) & 16(80,00 \%) & 17(85,00 \%) \\ \text { Melanoderma } & 03(17,65 \%) & 04(20,00 \%) & 03(15,00 \%)\end{array}$

Tabagismo

$\begin{array}{llll}\operatorname{Sim} & 14(82,35 \%) & 19(95,00 \%) & 17(85,00 \%) \\ \text { Não } & 03(17,65 \%) & 01(05,00 \%) & 03(15,00 \%)\end{array}$

Etilismo

$\begin{array}{llll}\text { Sim } & 12(70,59 \%) & 15(75,00 \%) & 16(80,00 \%) \\ \text { Não } & 05(29,41 \%) & 05(25,00 \%) & 04(15,00 \%)\end{array}$

Localização

$\begin{array}{clll}\text { Língua } & 10(58,83 \%) & 07(35,00 \%) & 07(35,00 \%) \\ \text { Soalho } & 04(23,53 \%) & 06(30,00 \%) & 05(25,00 \%) \\ \text { Palato duro } & 02(11,76 \%) & 01(05,00 \%) & 01(05,00 \%) \\ \text { Mucosa jugal } & 01(05,88 \%) & 01(05,00 \%) & 01(05,00 \%) \\ \text { Gengiva } & 00(00,00 \%) & 00(00,00 \%) & 00(00,00 \%) \\ \text { Trígono retromolar } & 00(00,00 \%) & 04(20,00 \%) & 06(30,00 \%) \\ \text { Rebordo alveolar } & 00(00,00 \%) & 01(05,00 \%) & 00(00,00 \%)\end{array}$

A análise histopatológica mostrou que todos os casos apresentaram o diagnóstico de CECO. O estágio morfológico mostrou que a maioria dos casos apresentou grau de diferenciação I e II (ver tabela 3). 
Tabela 3: Distribuição do grau histopatológico de diferenciação dos casos de CECO selecionados para o estudo

\begin{tabular}{cccc}
\hline $\begin{array}{c}\text { Grau de diferenciação } \\
\text { histopatológica }\end{array}$ & $\begin{array}{c}\text { Grupo I } \\
(\mathbf{n = 1 7 )}\end{array}$ & $\begin{array}{c}\text { Grupo II } \\
\mathbf{( n = 2 0 )}\end{array}$ & $\begin{array}{c}\text { Grupo III } \\
\mathbf{( n = 2 0 )}\end{array}$ \\
\hline Grau I & $04(23,53 \%)$ & $07(35,00 \%)$ & $06(30,00 \%)$ \\
Grau II & $12(70,59 \%)$ & $10(50,00 \%)$ & $13(65,00 \%)$ \\
Grau III & $01(05,88 \%)$ & $03(15,00 \%)$ & $01(05,00 \%)$ \\
\hline
\end{tabular}

A descrição detalhada acerca do estadiamento do tumor dos casos selecionados está mostrada na tabela abaixo (ver tabela 4).

Tabela 4: Estadiamento clínico dos casos selecionados para o presente estudo.

\begin{tabular}{|c|c|c|c|}
\hline $\begin{array}{l}\text { Estadiamento } \\
\text { clínico }\end{array}$ & Grupo I $(n=17)$ & Grupo II $(n=20)$ & Grupo III $(n=20)$ \\
\hline \multicolumn{4}{|l|}{$\mathbf{T}$} \\
\hline 1 & $00(00,00 \%)$ & $01(05,00 \%)$ & $01(05,00 \%)$ \\
\hline 2 & $05(29,41 \%)$ & $04(20,00 \%)$ & $04(20,00 \%)$ \\
\hline 3 & $01(05,88 \%)$ & $02(10,00 \%)$ & $01(05,00 \%)$ \\
\hline 4 & $03(17,65 \%)$ & $08(40,00 \%)$ & $08(40,12 \%)$ \\
\hline \multicolumn{4}{|l|}{$\mathbf{N}$} \\
\hline 0 & $06(35,29 \%)$ & $03(15,00 \%)$ & $04(20,00 \%)$ \\
\hline 1 & $02(11,76 \%)$ & $06(30,00 \%)$ & $05(25,00 \%)$ \\
\hline 2 & $01(05,88 \%)$ & $04(20,00 \%)$ & $05(25,00 \%)$ \\
\hline 3 & $00(00,00 \%)$ & $02(10,00 \%)$ & $00(00,00 \%)$ \\
\hline \multicolumn{4}{|l|}{ M } \\
\hline 0 & 09 (52.94\%) & $15(75,00 \%)$ & $13(65,00 \%)$ \\
\hline 1 & $00(00,00 \%)$ & $00(00,00 \%)$ & $01(05,00 \%)$ \\
\hline Desconhecido & $08(47,06 \%)$ & $05(25,00 \%)$ & $06(30,00 \%)$ \\
\hline
\end{tabular}




\subsection{Imunoexpressão de CD68 e CD163}

A partir dos registros fotográficos dos casos de CECO, foi possível visualizar numerosas células CD68+ e CD163+. As células CD68+ foram reconhecidas como sendo de marcação citoplasmática, enquanto células CD163+ foram reconhecidas através do seu padrão de marcação de superfície, mas também citoplasmática. A partir da avaliação de áreas consecutivas para esses imunomarcadores, foram quantificadas as células CD68+ e CD163+. A quantificação exibiu ligeiro predomínio de células CD68+, seguida por células CD163+, no estroma tumoral e nos ninhos intratumorais dos grupos I, II e III. Considerando ambas as porções (ET e NT), não foi possível observar diferenças na expressão de CD68 comparando os grupos I, II e III ( $p>0,05)$. A imunopositividade de CD163 para a soma desses compartimentos também não mostrou diferenças quando comparamos estes grupos $(p>0,05)$. Pela técnica de dupla marcação imunoistoquímica, foi possível encontrar numerosas células CD68+/CD163+, confirmando a presença de macrófagos M2 (ver figuras 2, 3 e 4).

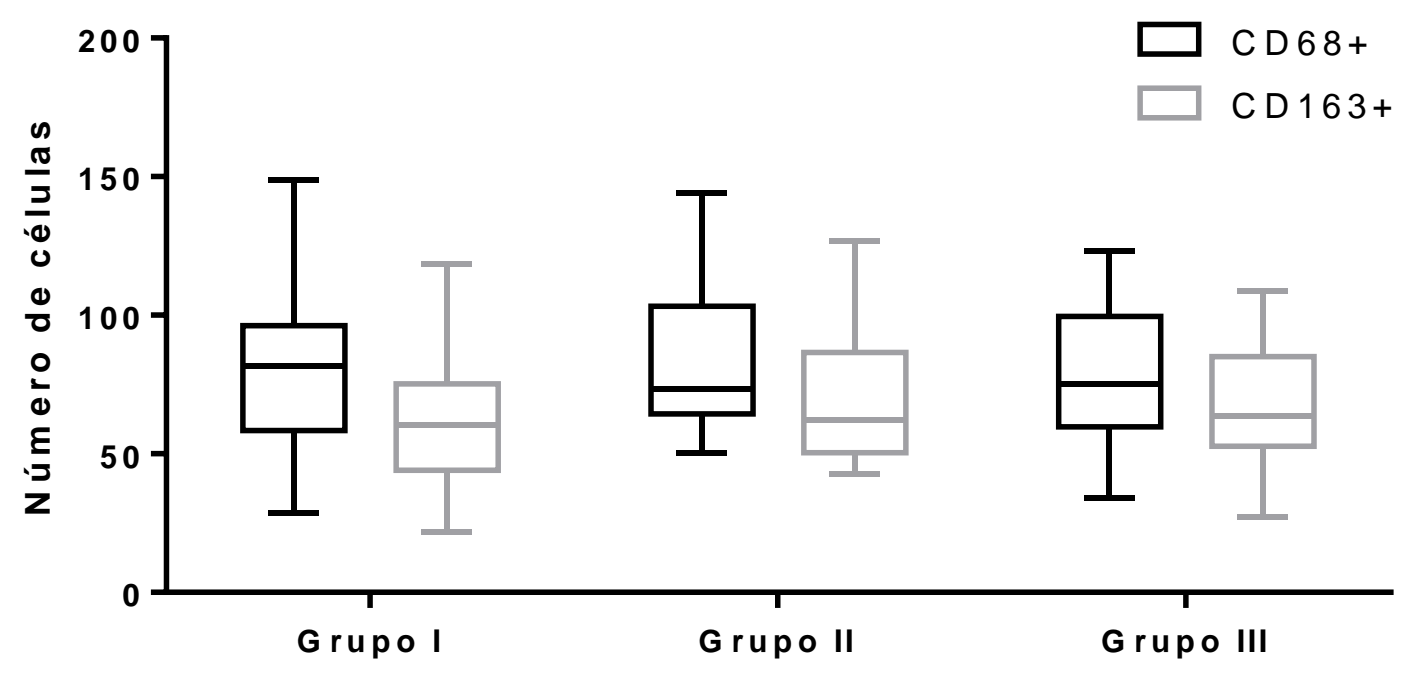

Figura 2: Quantificação de marcadores para macrófagos. $O$ eixo $Y$ indica a média do número total (incluindo ET e NT) de células imunopositivas para CD68 e CD163 por campo de x400 de magnificação. No eixo $X$, estão indicados os casos de CECO de diferentes grupos etários. 


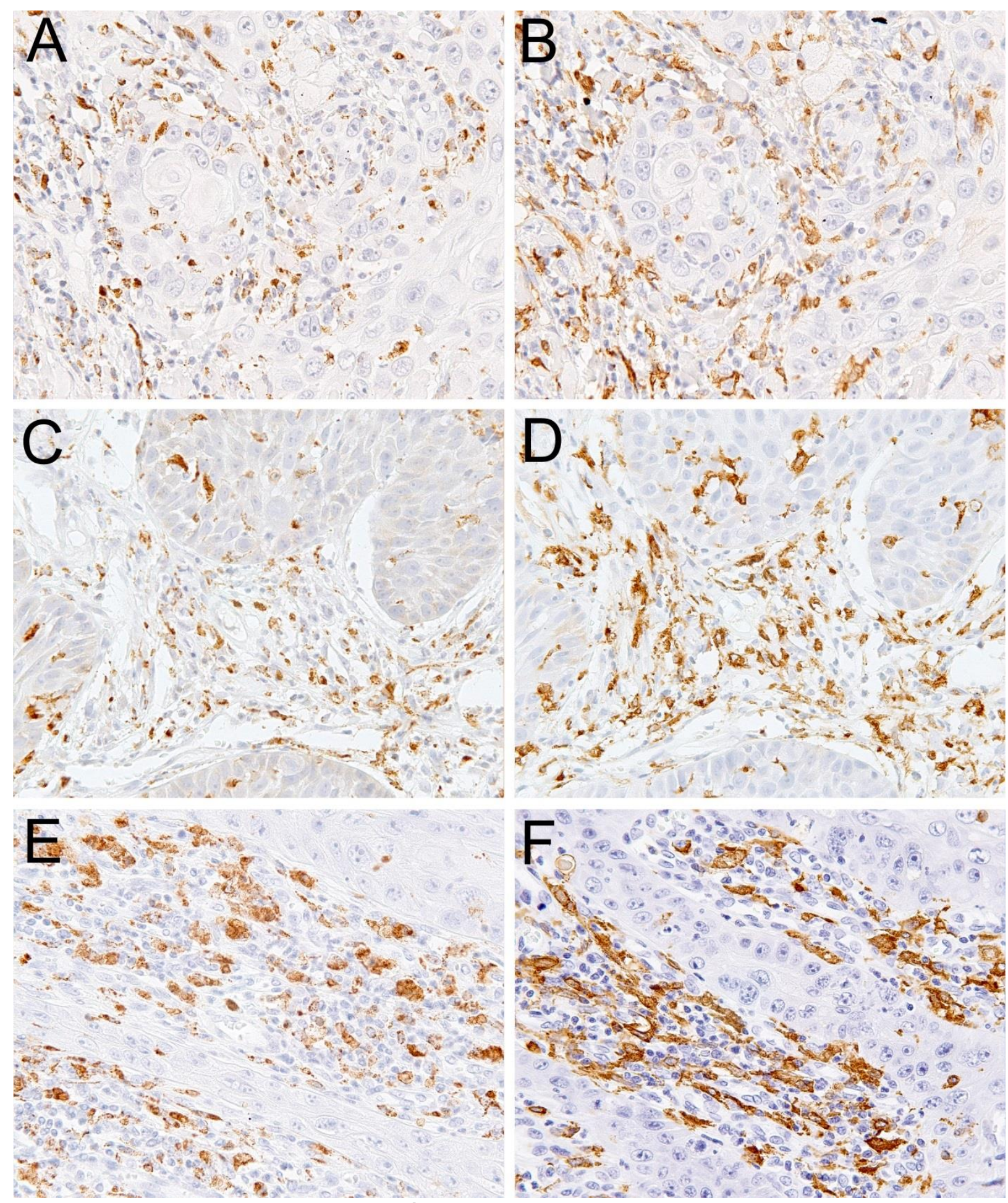

Figura 3: Imunoexpressão de macrófagos nos diferentes grupos analisados: presença de células CD68+ (A, x400) e CD163 (B, x400) em pacientes do grupo I; de células CD68+ (C, x400) e CD163+ (D, x400) em pacientes do grupo II e; de células CD68+ (E, x400) e CD163+ (F, x400) em pacientes do grupo III. 

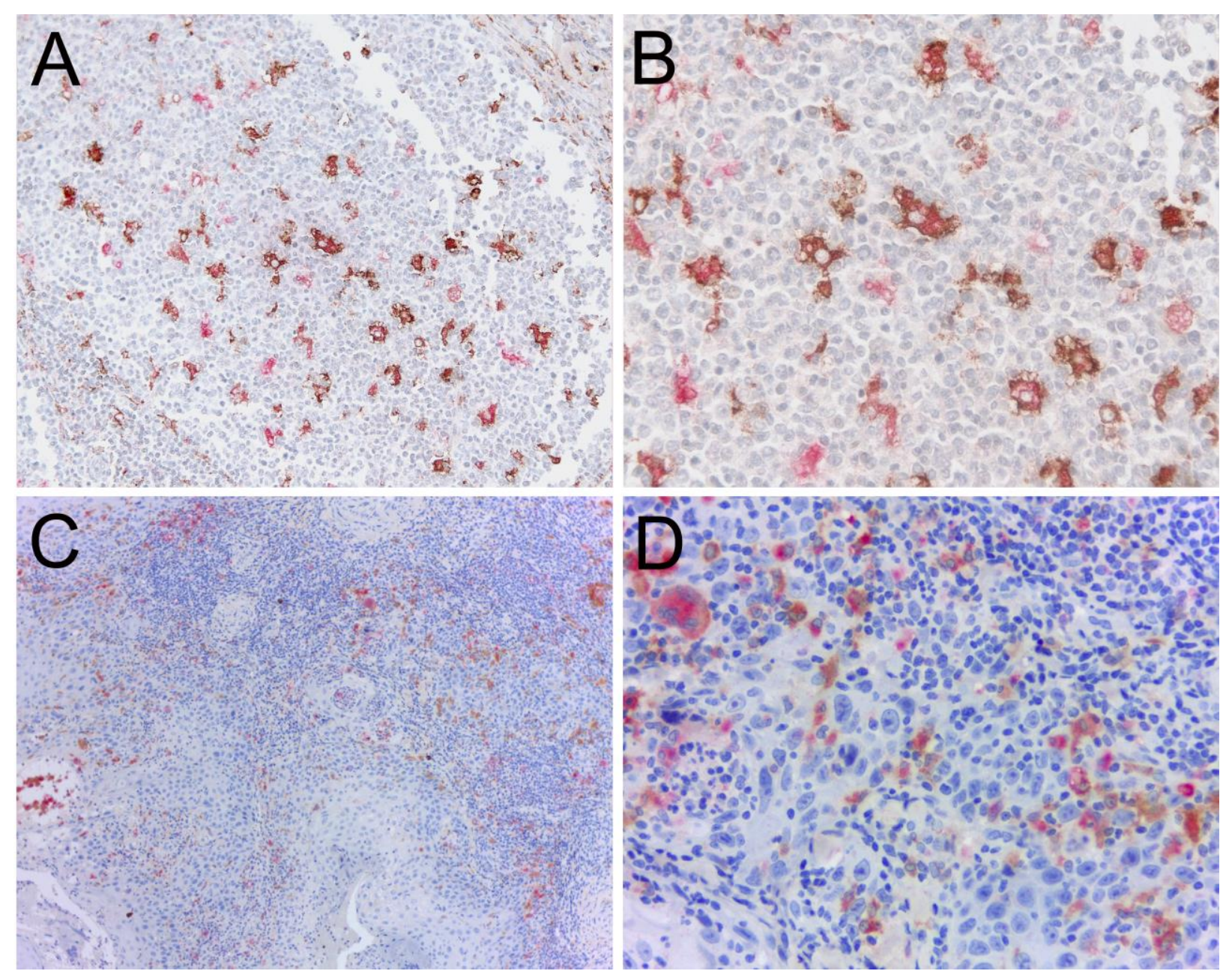

Figura 4: Dupla marcação imunoistoquímica: Fragmento de tonsila palatina utilizado como controle positivo para imunomarcação dupla, onde a coloração citoplasmática do marcador CD68 (vermelho) foi conferida pelo Permanent Red, enquanto a marcação de CD163 (marrom) foi conferida pelo cromógeno DAB (A: x200; B: x400). Caso de CECO representativo (grupo III) exibindo numerosas células CD68+/CD163+ (C: x100; D: x400).

Com relação ao estroma tumoral, a média de células CD68+ foi de 62,20 no grupo I, de 64,42 no grupo II e de 63,84 no grupo III. A média de células CD163+ nesta mesma localização foi de 50,05 no grupo I, de 56,20 no grupo II e de 54,86 no grupo III, não exibindo diferenças significantes quando feita a comparação entre os grupos. A imunoexpressão dos marcadores de macrófagos foi visualizada nos NTs em menor frequência comparado ao estroma tumoral, exibindo contagem média de células CD68+ de 15,65 no grupo I, de 18,72 no grupo II e de 15,30 no grupo III, enquanto a positividade para CD163+ mostrou médias de 10,96 no grupo I, de 13,95 no grupo II e de 12,57 no grupo III (ver tabela 5). 
Tabela 5: Distribuição média \pm DP das células imunopositivas para CD68 e CD163 nos compartimentos tumorais (NT) e estromal (ES) no CECO de diferentes grupos analisados.

\begin{tabular}{cccc}
\hline $\begin{array}{c}\text { Contagem de células } \\
(\text { médias } \pm \text { DP) }\end{array}$ & Grupo I $(\mathbf{n = 1 7})$ & Grupo II $(\mathbf{n = 2 0})$ & Grupo III $(\mathbf{n}=\mathbf{2 0})$ \\
\hline Tumor CD68+ & $15,65 \pm 12.55$ & $18,72 \pm 11.92$ & $15,30 \pm 10.59$ \\
Estroma CD68+ & $62,20 \pm 35.84$ & $64,42 \pm 26.70$ & $63,84 \pm 21.47$ \\
Total CD68+ & $77,85 \pm 31.55$ & $83,15 \pm 26.02$ & $79,15 \pm 24.59$ \\
Tumor CD163+ & $10,96 \pm 11.19$ & $13,95 \pm 08.66$ & $12,57 \pm 10.86$ \\
Estroma CD163+ & $50,05 \pm 29.42$ & $56,20 \pm 24.07$ & $54,86 \pm 19.16$ \\
Total CD163+ & $61,02 \pm 26.85$ & $70,15 \pm 23.46$ & $67,43 \pm 22.08$ \\
\hline
\end{tabular}

\subsection{Imunoexpressão de CD34 e D2-40}

Os microvasos sanguíneos identificados pela positividade do imunomarcador CD34 (reconhecidas pela coloração em membrana de endotélio vascular) foram observados em todos os casos de todos os grupos (I, II e III), assim como a microvasculatura linfática reconhecidos pela imunopositividade do marcador D2-40.

O número de microvasos corados por CD34 foram significativamente superiores daqueles corados por D2-40, em todos os grupos analisados. As médias da DMVS (densidade microvascular sanguínea) foram de 17,10 no grupo I, de 16,69 no grupo II e de 16,03 no grupo III. A DMVL (densidade microvascular linfática) exibiu médias de 7,45 para o grupo I, de 7,43 para o grupo II e de 7,37 para o grupo III. A análise estatística evidenciou diferença significante entre a frequência vascular sanguínea e linfática no grupo I $(p<0,0001)$, grupo II $(p<0,0001)$ e grupo III $(p<0,0001)$. No entanto, a expressão de células endoteliais CD34+ nos diferentes grupos não exibiu diferenças $(p>0,05)$. $O$ mesmo achado pode ser observado quanto à expressão de células endoteliais D2-40+, comparando os grupos I, II e III $(p>0,05)$ (ver figuras 5 e 6 ). 


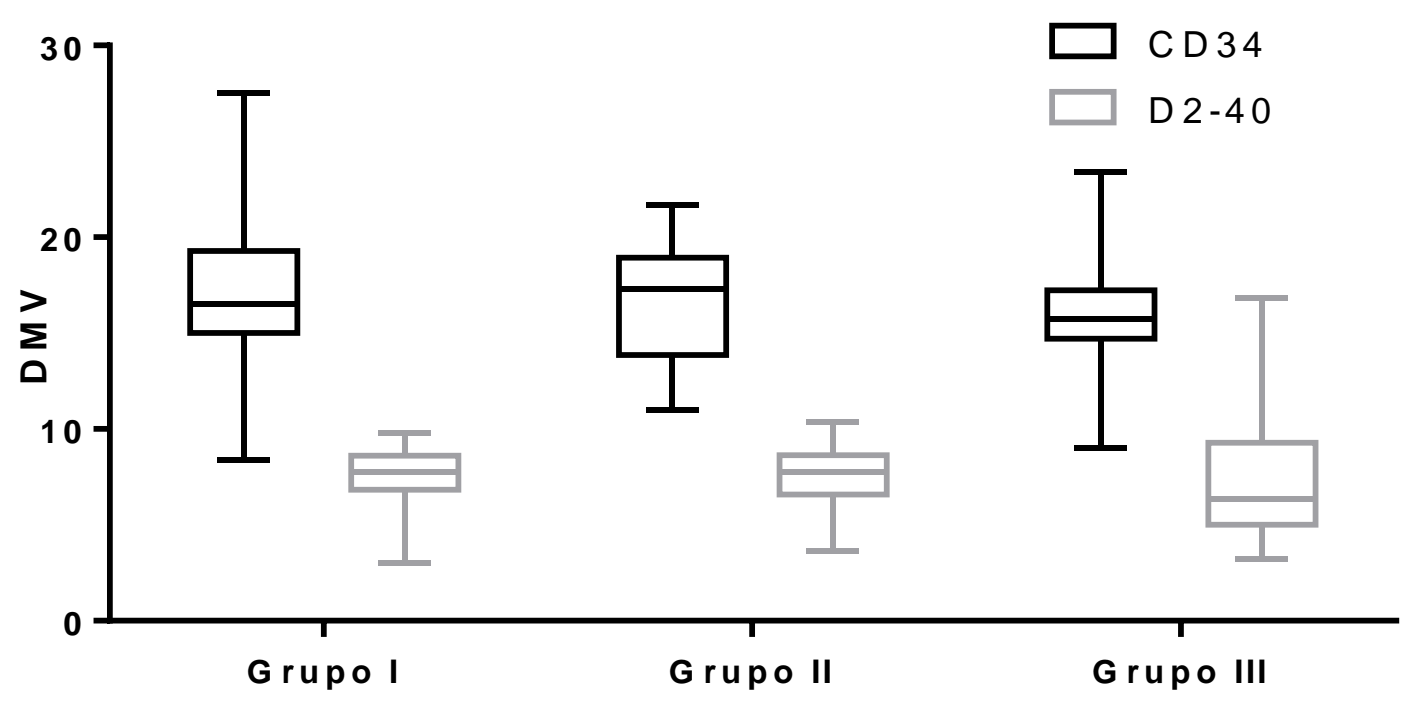

Figura 5: Determinação da DMV sanguínea e linfática no CECO. O eixo $Y$ indica as médias de estruturas vasculares positivas para CD34 e D2-40 na porção estromal, por campo de x400 de magnificação. No eixo X, estão indicados os casos de CECO de diferentes grupos etários. 


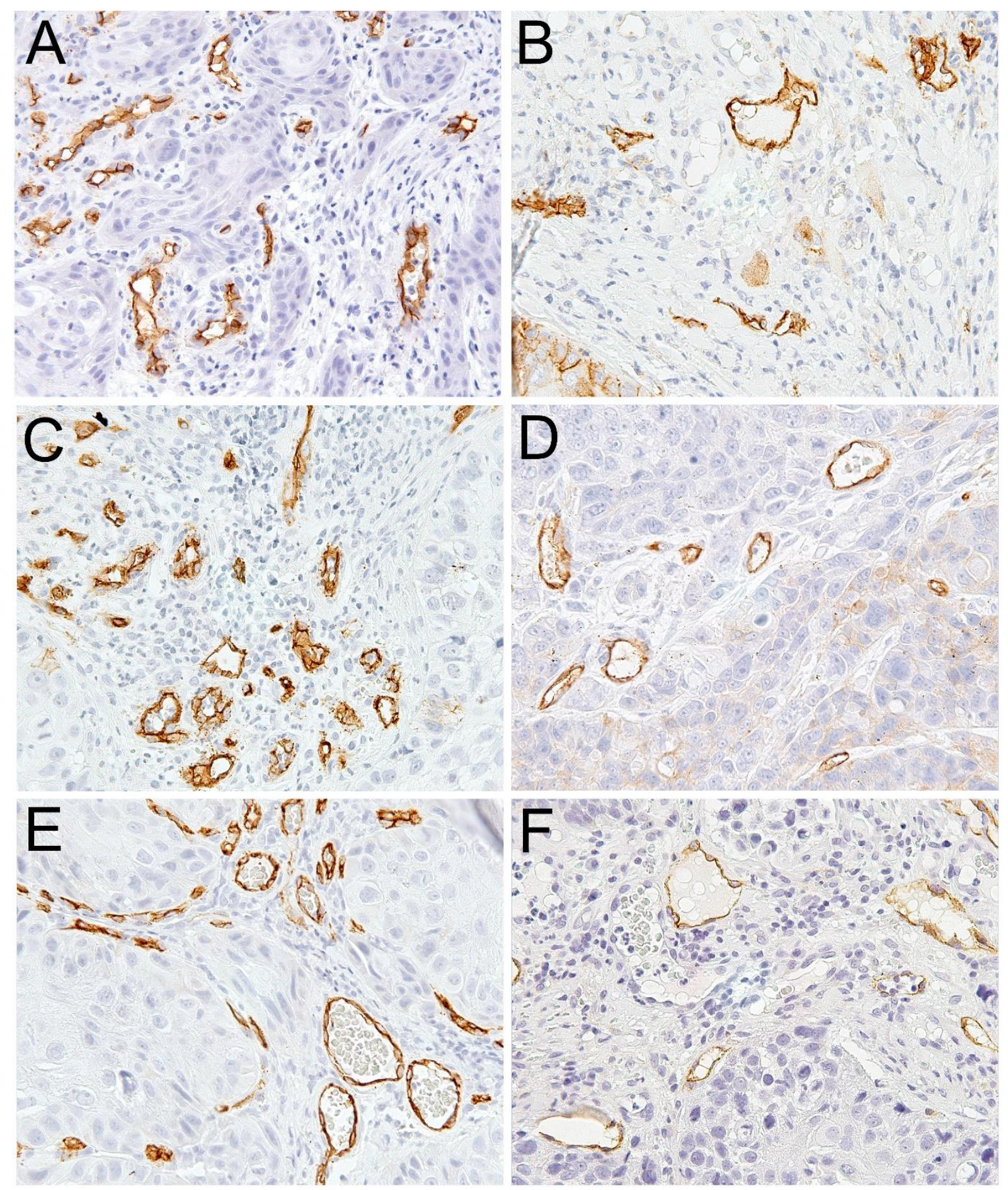

Figura 6: Visualização de estruturas vasculares sanguíneas e linfáticas, por meio dos imunomarcadores CD34 e D2-40, respectivamente, no CECO: Presença de vasos sanguíneos $(\mathbf{A}, \mathrm{x} 400)$ e linfáticos $(\mathbf{B}, \mathbf{x} 400)$ em pacientes do grupo I; presença de vasos sanguíneos (C, x400) e linfáticos (D, x400) em pacientes do grupo II; presença de vasos sanguíneos (E, x400) e linfáticos em pacientes do grupo III (F, x400). Note a quantidade significantemente maior de vasos sanguíneos quando comparados aos vasos linfáticos presentes no CECO dos três grupos etários analisados. 
Com relação aos cálculos para AMV (área microvascular), somente no grupo I foi observada média de AMVS superior $\left(364,16 \mu^{2}\right)$ à $\operatorname{AMVL}\left(330,33 \mu^{2}\right)$, sem diferenças significantes $(p=0,313)$, enquanto $\circ$ grupo II obteve um maior média de AMVL $\left(342,12 \mu^{2}\right)$ com relação à AMVS $\left(316,62 \mu^{2}\right)$, sem diferenças significantes ( $p=0,777)$, assim como no grupo III, com AMVL $\left(410,07 \mu^{2}\right)$ e AMVS $\left(343,95 \mu^{2}\right)$, não observando diferença significante $(p=0,522)$. Além disso, não foi possível verificar diferenças na AMVS nos três grupos estudados $(p=0,575)$, bem como na AMVL $(p=0,613)$ (ver figura 7$)$.

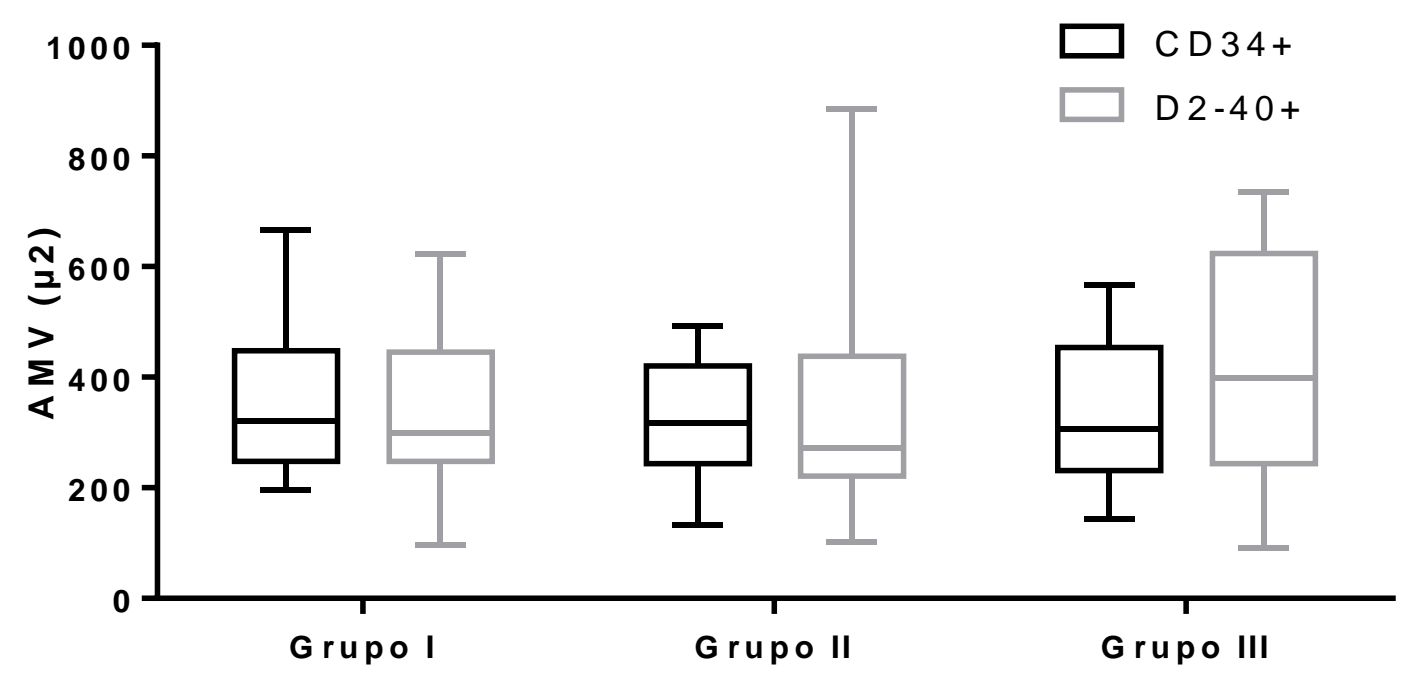

Figura 7: AMV sanguínea e linfática no $C E C O$. $O$ eixo $Y$ indica a área média de estruturas vasculares positivas para CD34 e D2-40 na porção estromal, por campo de $\times 400$ de magnificação. No eixo X, estão indicados os casos de CECO de diferentes grupos etários.

Na determinação da AVT, verificamos uma maior área encontrada de vasos sanguíneos no estroma tumoral em relação aos vasos linfáticos em ambos os grupos. Assim, AVTS evidenciou medias de 5062,71 $\mu^{2}$ para o grupo I, de 4841,56 $\mu^{2}$ para o grupo II e de 5081,36 $\mu^{2}$ para o grupo III. Fazendo uma análise comparativa, não é possível observar diferenças significantes entre os grupos etários ( $p>0,05)$. A AVTL, exibindo médias de 2563,34 $\mu^{2}$ para o grupo I, de 2272, $79 \mu^{2}$ para o grupo II e 2539,45 $\mu^{2}$ para o grupo III, também não evidenciou diferenças na comparação entre os grupos I, II e III ( $p=0,942)$. Outro achado importante foi que, independente da faixa etária, podemos observar diferenças entre a AVTS e AVTL, tal como 
observado no grupo I ( $p<0,0001)$, no grupo II $(p<0,0001)$ e no grupo III $(p<0,0001)$ (ver figura 8).

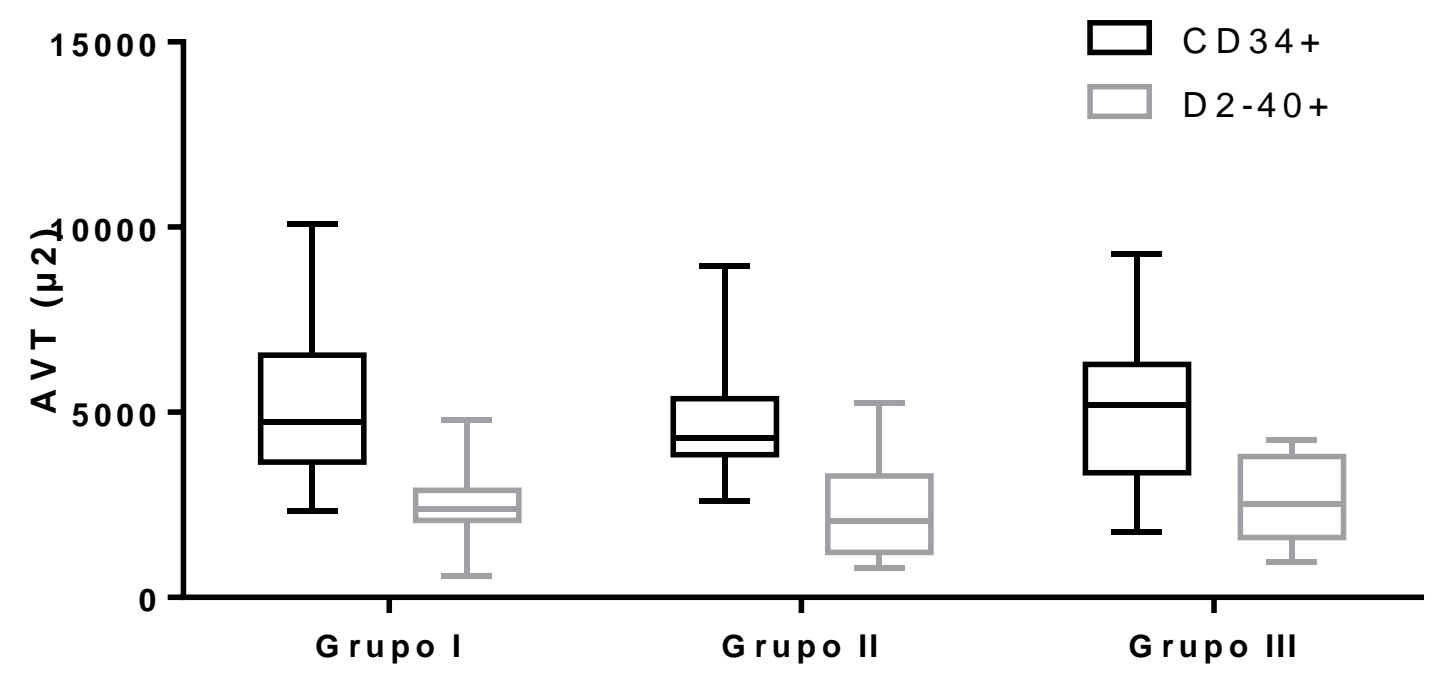

Figura 8: AVT sanguínea e linfática no CECO. O eixo $\mathrm{Y}$ indica as médias das áreas vasculares positivas para CD34 e D2-40 na porção estromal, por campo de x400 de magnificação. No eixo X, estão indicados os casos de CECO de diferentes grupos etários.

\subsection{Correlação entre imunoexpressão de macrófagos e densidade microvascular}

A análise de macrófagos e estruturas vasculares (DMVS) revelou não haver correlação entre CD68 e CD34 nos grupos I $(p=1.00)$, II $(p=0,365)$ e III $(p=0,265)$, Avaliando macrófagos CD163+ e vasos linfáticos CD34+, pode ser observado o mesmo padrão encontrado na relação CD68-CD34, onde não se pode constatar correlação nos grupos I ( $p=0.131)$, II $(p=0,124)$ e III $(p=0.314)$.

Avaliando os imunomarcadores CD68 e D2-40 (DMV), não foi possível observar correlação nos grupos I ( $p=0.619)$, II $(p=0.592)$ e III $(p=0.619)$. Similarmente, o teste utilizado também não exibiu correlação entre CD163 e D2-40 (DMV) nos grupos I $(p=1.00)$, II $(p=1.00)$ e III $(p=0.131)$.

Similarmente, não houve diferenças quando correlacionando marcadores macrofágicos e angiogênicos entre pacientes com $<40$ anos e $>40$ anos, e $<65$ anos e $>65$ anos. 


\section{DISCUSSÃO}




\section{DISCUSSÃO}

Nas últimas décadas, estudos epidemiológicos têm revelado um aumento significativo no número de indivíduos jovens afetados pelo $\mathrm{CECO}$. A análise do grupo de pacientes jovens e a comparação com pacientes idosos afetados pelo CECO (pacientes entre a quinta e sexta décadas de vida) têm exibido resultados divergentes quanto ao perfil destes pacientes (Zhang et al., 2018). Além disso, a definição etária para pacientes jovens também se mostra variada. Seguindo estudos prévios, consideramos em nosso estudo os pacientes jovens como aqueles com menos de 40 anos (Moura et al., 2016; Sgaramella et al., 2016). O grupo de pacientes de meia idade foi definido como aqueles com idade entre 40 e 65 anos, e pacientes idosos acima de 65 anos (Sgaramella et al., 2016).

Uma alta prevalência de acometimento pelo CECO em pacientes do gênero masculino é observada comumente na população afetada em geral. Em pacientes jovens, também é encontrado frequências similares (Ribeiro et al., 2009; Troeltzch et al., 2014; Santos et al., 2016), em concordância com os dados da amostra verificada no presente estudo ( $82 \%$ de 17 casos). Ao avaliar uma grande quantidade de casos de CEC de língua em pacientes jovens (117 casos ou 29\% da amostra total estudada), Farquhar e colaboradores (2018) observaram ambos os gêneros com a mesma proporção de acometimento (Farquhar et al., 2018). No entanto, também é possível encontrar estudos apresentando alto índice de mulheres jovens (Harris et al., 2011; Patel et al., 2011).

Questionamentos sobre a associação entre o consumo de tabaco e álcool no CECO em pacientes jovens vêm sendo feitos. Mackenzie e colaboradores (2000) levantaram a hipótese de que estes hábitos podem não estar presentes em pacientes jovens (Mackenzie et al., 2000). Zhang e colaboradores (2016), avaliando casos de CECO, afetando a língua, verificaram uma maior porcentagem destes hábitos em pacientes de meia-idade e uma pequena porcentagem em pacientes jovens (Zhang et al., 2016). Contrariamente, Ribeiro e colaboradores (2009), observaram que, dentre os pacientes jovens analisados, a maioria apresentava o hábito do tabagismo e etilismo de modo exagerado (Ribeiro et al., 2009). Miranda Galvis e colaboradores (2018) também não observaram diferenças nas frequências destes hábitos em pacientes jovens e idosos (Miranda Galvis et al., 2018). 
Similarmente, em nosso estudo o consumo de tabaco e álcool em pacientes do grupo I (jovens) foi semelhante com os demais grupos etários estudados.

Fatores prognósticos como o grau de diferenciação dos tumores também tem sido analisado objetivando a análise comparativa entre CECO afetando pacientes jovens e idosos. Veness e colaboradores (2003) e Zhang e colaboradores (2017) mostraram alta frequência de CECOs grau III em jovens (Veness et al., 2003; Zhang et al., 2017). Já Manuel e colaboradores (2003) apontaram alta incidência de CECOs bem diferenciados no mesmo grupo etário (Manuel et al., 2003). Os achados do nosso estudo mostraram predominância de CECOs moderadamente diferenciados em pacientes jovens, assim como nos demais grupos estudados, não havendo diferença significante.

Dentre os pontos analisados no perfil do CECO relacionado à idade, poucos estudos avaliam o papel e funcionamento das células envolvidas no microambiente tumoral (Siriwardena et al., 2007; Fonseca et al., 2014; Miranda Galvis et al., 2018; Miranda Galvis et al., 2018). Dos vários componentes celulares, os macrófagos são os mais abundantes e conhecidos pelo seu papel na progressão tumoral, associados com a capacidade de invasão de células tumorais, aumento da motilidade celular, crescimento tumoral persistente, estimulo angiogênico e com a supressão da resposta antitumoral (Petruzzi et al., 2016, Alves et al., 2018). Nestas investigações, a realização de procedimentos de IQ vem sendo amplamente utilizados para a detecção e tipificação de macrófagos (Petruzzi et al., 2017; Alves et al., 2018; Evrard et al., 2019).

Convencionalmente, o imunomarcador CD68 é o mais utilizado para detecção de MATs nos mais variados tipos de neoplasias malignas, incluindo câncer de pulmão (Feng et al., 2014; Pei et al., 2014; Mei et al., 2016), câncer de ovário (Zhang et al., 2014; Zhu et al., 2016; Yuan et al., 2017), câncer de mama (Zhang et al., 2013; Gwak et al., 2015; Yang et al., 2015; Zhao et al., 2017) e no CECO (Costa et al., 2013; Ni et al., 2015; Weber et al., 2016). Sua expressão tem sido descrita em localização majoritária no estroma tumoral e em menor número nas ilhas tumorais. A utilização do marcador CD163 de maneira isolada também têm sido encontrados para análise de MATs, a exemplo de investigações no câncer de pulmão (Carus et al., 2013) e no próprio CECO (Wang et al., 2014; Fujita et al., 2014, Matsuoka et al., 2014), onde sua imunomarcação também é visualizada mais densamente na porção 
do estroma tumoral. Além disso, a utilização conjunta dos marcadores CD68 e CD163 também é frequentemente observada em análises de MATs no CECO (Fujii et al., 2012; He et al., 2014; Hu et al., 2016).

Apesar da detecção e quantificação da imunopositividade para MATs serem de grande importância como marcador prognóstico, a identificação do fenótipo dos macrófagos tem explicado os eventos relacionados ao desenvolvimento das neoplasias malignas, principalmente considerando a atuação dos macrófagos com fenótipo M2, com papel chave na progressão tumoral. Similarmente aos achados encontrados em outros tumores sólidos, a predominância do fenótipo M2 tem sido observada no CECO (Mori et al., 2011; Weber et al., 2016; Alves et al., 2018). Assim, em nosso estudo, usando cortes histológicos sequenciais, além do marcador CD68 (que reconhece os macrófagos com fenótipo M1 e M2), foi incluído o marcador CD163 (específico para fenótipo M2) visando adequada caracterização da polarização dos macrófagos.

A frequência de MATs tem sido associados com o grau de diferenciação celular (Bôas et al., 2013), estadiamento clínico (Marcus et al., 2004; Weber et al., 2016) e sobrevida (Liu et al., 2008; Balermpas et al., 2014; Hu et al., 2016), dentro do contexto da correlação clinicopatológica. No entanto, poucos estudos têm avaliado a frequência dos macrófagos em diferentes grupos etários, sendo o presente estudo o primeiro a enfatizar o impacto da idade sobre a participação dos macrófagos no CECO, por meio de composição de três grupos etários. Ni e colaboradores (2015), avaliando a importância da localização de macrófagos CD68+ em diferentes localizações, não observaram diferenças significantes quanto a expressão de células CD68+ no estroma e nos ninhos tumorais em pacientes com menos de 55 anos e acima de 55 anos (Ni et al., 2015). Os achados do nosso estudo sugerem não haver diferenças na frequência de macrófagos entre os grupos analisados, tanto no estroma quanto no compartimento intratumoral. Além disso, considerando a presença de macrófagos com atividade pró-tumoral (fenótipo M2), identificados pela imunopositividade simultânea para CD68 e CD163, também não foi possível observar diferenças, sugerindo a predominância de macrófagos M2 nos diferentes grupos etários.

A confirmação da polarização de macrófagos foi realizada por procedimentos de dupla marcação antigênica, utilizando os marcadores CD68 e CD163, que 
demonstrou a presença de numerosos macrófagos corados para ambos os anticorpos (CD68+/CD163+), caracterizando o predomínio de macrófagos M2 em faixas etárias distintas. Até o momento, nenhum estudo tem utilizado esta técnica para identificação de macrófagos no CECO. No CEC de lábio inferior (CECLI), Lucio e colaboradores (2016) analisou por meio desta técnica a frequência de macrófagos M1 e M2, observando predominância do fenótipo macrofágico M2 em estágios clínicos iniciais (Lucio et al., 2016). Wei e Hu-Jie (2018) discutem que a realização desta técnica é essencial para determinar o exato fenótipo dos MATs (Wei \& Hu-Jie, 2018).

A angiogênese e linfangiogênese são processos relacionados principalmente à capacidade funcional de mastócitos e macrófagos, tanto em condições fisiológicas quanto patológicas (Utrera-Barillas et al., 2010). O processo angiogênico no CECO está associado à liberação de mediadores químicos por células tumorais e células do sistema imune associadas ao tumor. $O$ fator de crescimento de endotélio vascular (VEGF) e VEGF-A são os principais fatores pró-angiogênicos e sua presença já foi relatada em vários estudos (Mãrgãritescu et al., 2010; Oliveira-Neto et al., 2010, Johnson \& Wilgus, 2014). Imunomarcadores como fator de von-Willebrand (Benevenuto et al., 2012; Bôas et al., 2013), CD31 (El-Rouby et al., 2010; Jung et al., 2015; Chawla et al., 2017) e CD34 (Ascani et al., 2005; Shahsavari et al., 2015) são os mais utilizados para a avaliação de estruturas microvasculares sanguíneas, enquanto o CD105 (endoglina) têm seu uso para investigação da neoangiogênese (Mãrgaritescu et al., 2008). Dentre os anticorpos encontrados, o CD34 é amplamente utilizado e confiável para a detecção destas estruturas, justificando o uso desse marcador no presente estudo.

A linfangiogênese consiste na proliferação de células endoteliais linfáticas e são induzidas por fatores de crescimento como VEGF-C, VEGF-D e fator de crescimento de hepatócito. A utilização da técnica de IQ também é bem estabelecida para o reconhecimento de vasos linfáticos em tecidos normais e neoplásicos (Raica et al., 2008). Os marcadores imunoistoquímicos para endotélio linfático incluem LYVE-1, VEGF-3 e D2-40 (podoplanina) (Corliss et al., 2016; Yamagata et al., 2017). Além de frequentemente utilizado em tumores, o marcador D2-40 se mostra altamente confiável para avaliação de vascularização tumoral, fundamentando a inclusão deste anticorpo em nosso estudo. 
Os valores de índice angiogênico e linfangiogênico são frequentemente avaliados, visando estabelecer correlações prognósticas no CEC, seja afetando os lábios, cavidade oral (Marurana-Ramirez et al., 2015; Alaeddini \& EtemadMoghadam, 2016; Abdul-Aziz et al., 2017) e orofaringe (Takagi et al., 2006). Um estudo feito por Alaeddini e Etemad-Moghadam (2016), analisando o complexo microvascular no CECO e CECLI observaram predominância de vasos sanguíneos sobre vasos linfáticos em ambas as lesões (Alaeddini e Etemad-Moghadam, 2016). Avaliando o CECO, Maturana-Ramírez e colaboradores (2015), também demonstraram uma grande quantidade de vasos sanguíneos do que vasos linfáticos, verificando inclusive uma correlação positiva entre a expressão de vasos sanguíneos e vasos linfáticos em pacientes com CECO, no entanto sem distinção etária, apresentando média de idade de 61,9 anos dos casos analisados (MaturanaRamírez et al., 2015). Nossos resultados também demonstraram uma DMVS (através do reconhecimento por endotélio vascular CD34+) superior à DMVL (reconhecida pela imunopositividade para endotélio D2-40+) em todos os grupos, mostrando que pacientes de diferentes idades parecem ter o mesmo perfil de frequência vascular sanguínea e linfática no CECO.

O papel da angiogênese vem sendo amplamente discutido no CECO, principalmente relacionado à progressão tumoral e metástase. Em neoplasias malignas, ocorre um "shift" no equilibro pró/antiangiogênico, em decorrência da liberação de fatores indutores de angiogênese por componentes do microambiente tumoral (Al-Abd et al., 2017). Mas, apesar das evidências obtidas até o momento, poucos estudos abordam o perfil angiogênico em pacientes jovens e idosos. Shao e colaboradores (2008), avaliando a presença de microvasos sanguíneos no CECO, afetando a língua, não observaram diferenças entre pacientes com menos de 40 anos (jovens) e acima de 40 anos (Shao et al., 2008). Benevenuto e colaboradores (2012), além de não verificar diferenças no índice de proliferação celular (verificado por análise da expressão de Ki-67), não encontraram diferenças na angiogênese (analisado por meio da expressão de vWf) de pacientes jovens ( $<40$ anos) e idosos (>50 anos). Do mesmo modo, nosso estudo mostrou não haver diferenças no perfil angiogênico e linfangiogênico quando comparados os diferentes grupos etários.

Além da frequência de vasos sanguíneos, uma detalhada análise da área das estruturas microvasculares linfáticas foi feita no presente estudo, de modo a verificar 
o padrão da dimensão dos vasos envolvidos em regiões tumorais no CECO, principalmente avaliando comparativamente os grupos etários. Este tipo de análise é observado em algumas lesões da região bucomaxilofacial, como queratocisto odontogênico (Gadbail et al., 2011), ameloblastoma/carcinoma ameloblástico (Sánchez-Romero et al., 2017) e cisto/granuloma periapical (Lima et al., 2011), porém pouca informação quanto à determinação da AMV é observada no CECO. Mãrgãritescu e colaboradores (2010) mostraram uma maior AMV no CECO quando comparado com lesões potencialmente malignas (lesões com diagnóstico microscópico de displasia epitelial) e mucosas orais normais. Quando analisando os dados obtidos com dois grupos etários distintos ( $<60$ anos e $>60$ anos) a partir de uma correlação clinicopatológica, não observaram diferenças na participação vascular (Mãrgãritescu et al., 2010). Sem mencionar ou analisar aspectos etários, Shivamallappa e colaboradores (2011) também utilizou metodologia de análise vascular semelhante e não observaram diferenças significantes entre mucosa oral normal, lesões potencialmente malignas (descrito como leucoplasias) e CECO. Dentre os nossos achados, não observarmos diferenças significativas na AVTS dentre os três grupos, sugerindo similaridades na área vascular de pacientes jovens e idosos. Além disso, realizamos os cálculos de AMVS, que também não exibiram diferenças significativas entre os grupos. Os resultados obtidos no presente estudo reforçam as conclusões de Benevenuto e colaboradores (2012), que sugerem que uma possível agressividade do CECO recentemente discutido em pacientes jovens provavelmente não está associada com a formação vascular sanguínea (Benevenuto et al., 2012).

De modo similar à análise da angiogênese, também investigamos a participação dos vasos linfáticos por meio da determinação da DMVL, AMVL e AVTL. Nossos dados mostraram além de uma expressão significantemente menor de D2-40 na microvasculatura tumoral quando comparados à imunoexpressão de CD34 em todos os casos, que todos os grupos possuem similaridades quanto à sua frequência, área total e dimensões vasculares médias. Com relação à DMVL, podem ser observados resultados semelhantes em publicações prévias (Moura et al., 2016; Sgaramella et al., 2016). Considerando a frequência considerável de metástase linfonodal e a dificuldade de detectá-lo clinicamente, Sgaramella e colaboradores (2016), avaliaram a expressão de podoplanina (D2-40) em células tumorais e na 
microvasculatura tumoral do $\mathrm{CECO}$, de língua, e observaram que não houve associação entre vasos linfáticos e as variáveis clinicopatológicas como gênero, estadiamento e, principalmente, à idade (Sgaramella et al., 2016). Moura e colaboradores (2016), alinhado com a temática da linfangiogenese no CECO de diferentes grupos etários, também não observaram diferenças na MDVL no CECO de pacientes jovens ( $\leq 40$ anos) e idosos (>50 anos) (Moura et al., 2016).

Com relação à $A V T L$ e $A M V L$ no $C E C O$, observamos poucas análises com proposta semelhante em CEC da região de cabeça e pescoço, além de variações na metodologia empregada. Uma publicação abordando linfagiogênese no CECO, que dentre as análises de correlação realizadas, foram divididas a amostra em 2 grupos etários (<63 anos; $\geq 63$ anos), observando DMVL ligeiramente superior no grupo <63 anos e AMVL ligeiramente superior no grupo $\geq 63$ anos, sem apresentar, no entanto, diferenças significativas após inferência estatística (Franchi et al., 2004).

Ressaltando a importância do melhor entendimento biológico deste tipo de tumor, mostramos, pela primeira vez, que, apesar das diferenças quanto a DMVS e DMVL no tecido tumoral, a configuração dimensional das estruturas sanguíneas e linfáticas parece ser semelhante em diferentes faixas etárias em pacientes com CECO.

O estudo da relação entre macrófagos e vascularização tumoral tem sido relatado por alguns trabalhos, porém poucos avanços no entendimento dos mecanismos tumorigênicos têm sido alcançados. Considerando a associação macrófagos-linfangiogenese em neoplasias malignas, um número bastante reduzido de estudos com esse tema tem sido encontrado na literatura cientifica. Corliss e colaboradores (2016) observaram um número quinze vezes menor de estudos deste tipo celular com a formação linfática quando comparados à sanguínea (Corliss et al., 2016). Em cavidade oral, o panorama é semelhante, tendo somente uma investigação sobre esta associação analisada no CECO (Yamagata et al., 2017). Além disso, poucos esforços têm sido feitos quanto à análise simultânea de macrófagos com os processos de remodelação vascular sanguínea e linfática (Corliss et al., 2016), sendo observado somente no câncer cervical (Utrera-Barillas et al., 2010) e gástrico (Wu et al., 2012). Considerando os poucos dados disponíveis, nosso estudo aborda, pela primeira vez, a associação de macrófagos com 
angiogênese e linfangiogênese de modo concomitante no CEC de cabeça e pescoço, especificamente no CECO.

Apesar do conhecido papel angiogênico dos macrófagos, não há um consenso sobre a relação dessas duas variáveis no CECO. El-Rouby (2010), avaliando lesões como CECO e carcinoma verrucoso oral (CVO), realizou uma análise de regressão linear que revelou que MATs (CD68+) podem estar associados com angiogênese (CD31+) (El-Rouby, 2010). Contrariamente, Bôas e colaboradores (2013) não encontraram correlação entre a densidade de macrófagos (CD68+) infiltrando o tumor e DMV ( $\left(\mathrm{Wf}_{+}\right)$, assim como Chawla e colaboradores (2017), que também não encontrou nenhuma influência da frequência de macrófagos (CD68+) na angiogênese (CD31+) em CECO, CVO e displasia epitelial oral (Chawla et al., 2017). Bôas e colaboradores (2013) sugerem, após análise de seus resultados, que a angiogênese pode não estar relacionada com a quantidade de macrófagos presentes no CECO, mas sim o perfil imunofenotípico predominante (Bôas et al., 2013). Nos três estudos mencionados acima, não há qualquer tipo de análise ou estratificação considerando diferentes grupos etários, o que dificulta um confronto com os resultados do presente estudo, que analisa pacientes jovens, de meia-idade e idosos.

Em nosso estudo, a correlação entre macrófagos e expressão vascular sanguínea mostrou uma ausência de associação entre essas variáveis nos grupos I, II e III. Somado ao achado de perfis similares de angiogênese em ambas as faixas etárias, sugerimos uma provável participação de outros componentes do microambiente tumoral na formação e manutenção vascular sanguínea do CECO em indivíduos de diferentes faixas etárias.

$\mathrm{Na}$ análise da relação entre MATs e linfangiogenese também não foi possível observar associação entre macrófagos CD68+/CD163+ e microvasculatura D2-40+ em ambos os grupos investigados. Sem distinção etária, Yamagata e colaboradores (2017), utilizaram os marcadores imunoistoquímicos CD163 e CD204 para identificação de macrófagos com fenótipo M2 e D2-40 para a detecção de vasos linfáticos no CECO e verificaram que altas densidades de macrófagos CD163+e CD204+ estão associadas com uma alta DMVL (Yamagata et al., 2017).

A análise da infiltração de macrófagos, em correlação com vasos sanguíneos e linfáticos, é de grande importância para uma melhor compreensão dos 
mecanismos tumorigênicos de tumores sólidos, principalmente no contexto dos avanços em terapias antineoplásicas imunomodulatórias. As terapias que tem como alvo os MATs se mostram relevantes, visando a inibição de crescimento tumoral e invasividade. A inibição de citocinas liberadas principalmente por células tumorais que atraem e alteram a configuração funcional de macrófagos apresentam um grande potencial para modular a interação entre essas células neoplásicas e MATs (Mancino e Lawrence, 2010), assim como a reprogramação fenotípica (M2 para M1) para inibição da progressão e metástase tumoral (Georgoudaki et al., 2016). A regulação da atividade angiogênica (Zhao \& Adjei, 2015) e linfangiogênica (Duong et al., 2012) também é vista como uma interessante alternativa para aplicação terapêutica, principalmente por meio da inibição de fatores de crescimento associadas com a formação vascular, objetivando o controle tumoral e metastático. Sendo assim, o uso complementar desses tipos de terapias se mostra promissor para incrementar a efetividade do tratamento de neoplasias malignas (Corliss et al., 2016; Mantovani et al., 2017).

Uma preocupação no manejo de pacientes idosos vem sendo observada em estudos relacionados ao tratamento do câncer de cabeça e pescoço. Em função de condições locais e sistêmicas de pacientes em idade senil, as opções terapêuticas, principalmente quando combinadas, podem levar a efeitos tóxicos relacionados ao tratamento e a comorbidades em grau mais severo que em pacientes jovens (Rijke et al., 1996). Assim, discute-se que a intensificação dessas terapias poderia trazer menos benefícios a estes pacientes em idade senil exigindo uma racionalização quanto a intensidade e dosimetria aplicadas. Por outro lado, essas limitações direcionam a um tratamento mais conservador, que pode resultar em pior desfecho clínico. Apesar disso, é possível observar que o manejo de pacientes jovens e idosos é similar, onde a decisão terapêutica é tomada de acordo com critérios clinicopatológicos (Gamez et al., 2019).

No contexto imunológico, acredita-se que os efeitos da imunossenescência podem afetar a quantidade e capacidade moduladora de células do sistema imune. Dentre os componentes deste sistema, os macrófagos podem estar envolvidos nesta desregulação, por exemplo, através de liberação de substâncias imunossupressoras, como as prostaglandinas. Além disso, é descrito que altos níveis de IL-10 em macrófagos podem ser encontrados nos idosos em comparação 
com jovens. A IL-10 está envolvida na mudança de um fenótipo macrofágico antiangiogênico e pró-inflamatório para um fenótipo pró-angiogênico e anti-inflamatório (Dace \& Apte, 2008). No presente estudo, é demonstrado que o perfil de frequência e polarização de macrófagos, bem como vasos sanguíneos e linfáticos envolvidos no CECO é semelhante em diferentes faixas etárias, sugerindo que a instituição de terapias que tem como alvos os MATs e o complexo microvascular poderiam ocorrer da mesma maneira em pacientes jovens, de meia-idade e idosos.

Assim, considerando o curso de envelhecimento do sistema imunológico com o tempo, nossos resultados indicam que a infiltração de macrófagos, exibindo fenótipo M2, e estruturas vasculares, com predomínio sanguíneo, se mantem com perfis similares, independentemente da idade do paciente acometido pelo CECO. Estudos adicionais devem ser realizados, focando em metodologias moleculares que permitam avaliar o estado funcional destas células e estruturas estromais em amostras similares ao proposto neste trabalho. 


\section{CONCLUSÕES}




\section{CONCLUSÕES}

De acordo com os resultados obtidos, pode-se concluir que:

- Os dados clinicopatológicos das amostras não evidenciaram diferenças quanto a gênero, hábitos como tabagismo e etilismo, localização do sítio primário do tumor, bem como o grau histológico dos tumores.

- A avaliação imunoistoquímica de macrófagos exibiram quantidades ligeiramente maiores de células CD68+, seguidas de células CD163+. A imunopositividade destes marcadores foi observada predominantemente no $E T$, sendo também vistas nos NTs. Considerando os grupos etários, não observamos diferenças significativas na expressão de CD68 e CD163.

- A determinação da microvasculatura sanguínea e linfática no CECO revelou DMVS (CD34+) significativamente maior quando comparado à DMVL (D2$40+$ ), em todos os grupos. A análise dimensional mostrou perfis similares na configuração vascular sanguínea e linfática em pacientes de diferentes idades, sem correlação com marcadores macrofágicos, sugerindo outros mecanismos angiogênicos.

Assim, mostramos que a presença de macrófagos M2 e vasos sanguíneos é mantida no CECO independente da idade do paciente afetado. Sugerimos, ao invés da imunossenescência, uma participação de mecanismos moleculares do microambiente tumoral na patogênese do CECO afetando pacientes jovens e idosos. 


\section{REFERÊNCIAS}




\section{REFERÊNCIAS}

Abdul-Aziz MA, Amin AK, El-Rouby DH, Shaker OG. Lymphangiogenesis in oral squamous cell carcinoma: Correlation with VEGF-C expression and lymph node metastasis. Int J Dent. 2017;2017:7285656.

Alaeddini M, Etermad-Moghadam S. Lymphangiogenesis in oral cavity and lower lip squamous cell carcinoma. Braz J Otorhinolaryngol. 2016 Jul-Aug;82(4):385-90.

Alves AM, Diel LF, Lamers ML. Macrophages and prognosis of oral squamous cell carcinoma: A systematic review. J Oral Pathol Med. 2018 May;47(5):460-467.

Al-Abd AM, Alamoudi AJ, Abdel-Naim AB, Osama AN, Ashour OM. Anti-angiogenic agents for the treatment of solid tumors: Potential pathways, therapy and current strategies - A review. J Adv Res. 2017 Nov;8(6):591-605.

Ascani G, Balercia, Messi L, Lupi L, Goteri G, Filosa A, Stramazzotti, Pieramici T, Rubini C. Angiogenesis in oral squamous cell carcinoma. Acta Otorhinolaryngol Ital. 2005 Feb; 25(1): 13-17.

Balermpas P, Rödel F, Liberz R, Oppermann J, Wagenblast J, Ghanaati S, Harter PN, Mittelbronn M, Weiss C, Rödel C, Fokas E. Head and Neck câncer after chemoradiotherapy correlates with CD163+ macrophages in primary tumour anc CD11b+ myeloid cells in recurrences. Br J Cancer. 2014 Oct 14;111(8):1509-18.

Benevenuto TG, Nonaka CF, Pinto LP, Souza LB. Immunohistochemical comparative analysis of cell proliferation and angiogenic index in squamous cell carcinomas of the tongue between young and older patients. Appl Immunohistochem Mol Morphol. 2012;20(3):291-7.

Bôas DS, Takiya CM, Gurgel CA, Cabral MG, Santos JN. Tumor-infiltrating macrophage and microvessel density in oral squamous cell carcinoma. Braz Dent J. 2013;24(3):194-9.

Bray F, Ferlay J, Soeriomataram I, Siegel RL, Torre LA, Jemal A. Global câncer statistics 2018: GLOBOCAN estimates of incidence and mortality worldwide for 36 cancer in 185 countries. CA Cancer J Clin. 2018 Nov;68(6):394-424.

Carus A, Ladekarl M, Hager H, Pilegaard H, Nielsen OS, Donskov F. Tumor-associated neutrophils and macrophages in non-small cell lung câncer: no immediated impacto n patient outcome. Lung Cancer. 2013 Jul; 81(1):130-7.

Caruso C, Buffa S, Candore G, Colonna-Romano G, Dunn-Walters D, Kipling D, Pawelec G. Mechanisms of immunosenescence. Immun Ageing. 2009 Jul 22;6:10.

Chawla $\mathrm{H}$, Urs $A B$, Augustine J. Association of macrophages with angiogenesis in oral epitelial dysplasia, oral verrucous cell carcinoma, and oral squamous cell carcinoma: An immunohistochemical study. Appl Immunohistochem Mol Morphol. 2017 Mar; 25(3): 203-208

Coffelt SB, Hughes R, Lewis CE. Tumor-associated macrophages: Effectors of angiogenesis and tumor progression. Biochim Biophys Acta. 2009 Aug;1796(1):11-8. 
Corliss BA, Azimi MS, Munson JM, Peirce SM, Murfee WL. Macrophages: An inflammatory link between angiogenesis and lymphangiogenesis. Microcirculation. 2016 Feb; 23(2):95121.

Costa SFS. Brennan PA, Gomez RS, Fregnani ER, Santos-Silva AR, Martins MD, CastroJunior G, Rahimi S, Fonseca FP. Molecular basis of oral squamous cell carcinoma in young patients: Is it any different from older patients? J Oral Pathol Med. 2018 Jul;47(6):541-546.

Chi AC, Day TA, Neville BW. Oral cavity and oropharyngeal squamous cell carcinoma - an update. CA Cancer J Clin. 2015 Sep-Oct;65(5):401-21.

Dace DS, Apte RS. Effect of senescence on macrophage polarization and angiogenesis. Rejuvenation Res. 2008 Feb;11(1):177-85.

Duong $\mathrm{T}$, Koopman $\mathrm{P}$, François $\mathrm{M}$. Tumor lymphangiogenesis as a potential therapeutic target. J Oncol. 2012;2012:204946.

El-Naggar AK, Chan JKC, Grandis JR, Takata T, Slootweg PJ. WHO classification of head and neck tumours. 4th edn. France: International Agency for Research on Cancer (IARC); 2017.

El-Rouby DH. Association of macrophages with angiogenesis in oral verrucous and squamous cell carcinomas. J Oral Pathol Med. 2010 Aug 1;39(7):559-64.

Evrard D, Szturz P, Tijeras-Raballand A, Astorgues-Xerri L, Paradis V, Raymond E, Albert S, Barry B, Faivre S. Macrophages in the microenvironment of head and neck câncer: potential targets for cancer terapy. Oral Oncol. 2019 Jan; 88: 29-38.

Fabriek BO, van Bruggen R, Deng DM, Ligtenberg AJ, Nazmi K, Schornagel K, Vloet RP, Dijkstra CD, van den Berg TK. The macrophage scavenger receptor CD163 functions as an innate imune sensor for bactéria. Blood. 2009 Jan 22;113(4):887-92.

Fang J, Li X, Ma D, Liu X, Chen Y, Wang Y, Lui VWY, Xia J, Cheng B, Wang Z. Prognostic significance of tumor infiltrating immune cells in oral squamous cell carcinoma. BMC Cancer. 2017 May 26;17(1):375.

Farnsworth $\mathrm{RH}$, Achen MG, Stacker AS. The evolving role of lymphatics in câncer metastasis. Curr Opin Immunol. 2018 Aug;53:64-73.

Farquhar DR, Tanner AM, Masood MM, Patel SR, Hackman TG, Olshan AF, Mazul AL, Zevallos JP. Oral tongue carcinoma among young patients: An analysis of risk factors and survival. Oral Oncol. 2018 Sep;84:7-11.

Ferlay J, Soerjomataram I, Ervik M, Dikshit R, Eser S, Mathers C, Rebelo M, Parkin DM, Forman D, D, Bray F. GLOBOCAN 2012 v1.0, Cancer Incidence and Mortalitity Worldwide: IARC CancerBase No. 11 [Internet]. Lyon, France: International Agency for Reserach on Cancer; 2013. http://globocan.iarc.fr. Acessado em maio de 2018.

Feng PH, Yu CT, Wu CY, Lee MJ, Lee WH, Wang LS, Lin SM, Fu JF, Lee KY, Yen TH. Tumor-associated macrophages in stage IIIA pN2 non-small call lung câncer after neoajuvant chemotherapy and surgery. Am J Transl Res. 2014 Oct 11;6(5):593-603. 
Fonseca FP, Coletta RD, Azevedo MB, Prado Ribeiro AC, Pires Soubhia AM, Miyahara GI, Carlos R, Farthing P, Hunter KD, Speight PM' Vargas PA, Almeida OP, Lopes MA, SantosSilva AR. Stromal myofibroblasts in squamous cell carcinoma of the tongue in young patients - a multicenter collaborative study. Oral Surg Oral Med Oral Pathol Oral Radiol. 2014 Oct;118(4):483-9.

Franchi A, Gallo O, Massi D, Baroni G, Santucci M. Tumor lymphangiogenesis in head and neck squamous cell carcinoma: a morphometric study with clinical correlations. Cancer. 2004 Sep 1;101(5):973-8.

Frare JC, Calone IS, Rangel ALCA, Bueno AG, Morais CF, Nagai HM, Kunz R, Lopes MA. Histopathological grading systems analysis of oral squamous cell carcinomas of young patients. Med Oral Patol Oral Cir Bucal. 2016 May; 21(3): e285-e298.

Fulop T, Larbi A, Witkowski JM, Kobt R, Hirowaka K, Pawelec G. Immunosenescence and câncer. Crit Rev Oncog. 2013;18(6):489-513.

Fujii N, Shomori K, Shiomi T, Nakabayashi M, Takeda C, Ryoke K, Ito H. Cancer-associated fibroblastos and CD163-positive macrophages in oral squamous cell carcinoma. J Oral Pathol Med. 2012 Jul;41(6):444-51.

Fujita Y, Okamoto M, Goda H, Tano T, Nakashiro K, Sugita A, Fujita T, Koido S, Homma S, Kawakami Y, Hamakawa $\mathrm{H}$. Prognostic significance of interleukin-8 and CD163-positive cell infiltration in tumor tissues in patients with oral squamous cell carcinoma. PLoS One. 2014 Dec 2;9(12):e110378.

Gadbail AR, Hande A, Chaudhary M, Nikam A, Gawande M, Patil S, Tekade S, Gondivkar S. Tumor angiogenesis in keratocystic odontogenic tumor assessed by using CD-105 antigen. J Oral Pathol Med. 2011 Mar;40(3):263-9.

Gamez ME, Kraus R, Hinni ML, Moore EJ, Ma DJ, Ko SJ, Rwigema JCM, McGee LA, Halyard MY, Buras MR, Foote RL, Patel SH. Treatment outcomes of squamous cell carcinoma of the oral cavity in young adults. Oral Oncol. 2018 Dec; 87:43-48.

Georgoudaki AM, Prokopec KE, Boura VF, Helqvist E, Sohn S, Õstling J, Dahan R, Harris R, Rantalainen M, Klevebring D, Sund M, Brage SE, Fuxe J, Rolny C, Li F, Ravetch JV, Karlsson MC. Reprogramminf tumor-associated macrophages by antibody targeting inhibits cancer progression and metastasis. Cell Rep. 2016 May 31;15(9):2000-11.

Gordon S, Taylor PR. Monocyte and macrophage heterogeneity. Nat Rev Immunol. 2005 Dec;5(12):953-64.

Gupta K, Metgud R. Evidences suggesting involvement of viruses in oral squamous cell carcinoma. Patholog Res Int. 2013; 2013:642496.

Gwak JM, Jang MH, Kim DI, Seo AN, Park SY. Prognostic value of tumor-associated macrophages according to histologic locations and hormone receptor status in breast câncer. PLoS One. 2015 Apr 17;10(4):e0125728.

Hanahan D, Coussens LM. Accessories to the crime: functions of cells recruited to the tumor microenvironment. Cancer Cell. 2012 Mar 20;21(3):309-22. 
Harris SL, Thorne LB, Seaman WT, Hayes DN, Couch ME, Kimple RJ. Association of p16 (INK4a) overexpression with improved outcomes in young patients with squamous cell câncer of the oral tongue. Head Neck. 2011 Nov;33(11):1622-7.

He KF, Zhang L, Huang CF, Ma SR, Wang YF, Wang WM, Zhao ZL, Liu B, Zhao YF, Zhang WF, Sun ZJ. CD163+ tumor-associated macrophages correlated with poor prognosis and câncer stem cells in oral squamous cell carcinoma. Biomed Res Int. 2014; 2014:838632.

Hirota SK, Braga FP, Penha SS, Sugaya NN, Migliari DA. Risk factors for oral squamous cell carcinoma in young and older Brazilian patients: a comparative analysis. Med Oral Patol Oral Cir Bucal. 2008 Apr 1;13(4): E227-31.

Holness CL, Simmons DL. Molecular cloning of CD68, a human macrophage marker related to lysosomal glycoproteins. Blood. 1993 Mar 15;81(6):1607-13.

Hu Y, He MY, Zhu LF, Yang CC, Zhou ML, Wang Q, Zhang W, Zheng YY, Wang DM, Xu ZQ, Wu YN, Liu LK. Tumor-associated macrophages correlate with the clinicopatological features and poor outcomes via inducing epitelial to mesenchymal transition in oral squamous cell carcinoma. J Exp Clin Cancer Res. 2016 Jan 15; 35:12.

Hussein AA, Helder MN, de Visscher JG, Leemans CR, Braakhuis BJ, de Vet HCW, Forouzanfar T. Global incidence of oral and oropharynx cancer in patients younger than 45 years versus older patients: A systematic review. Eur J Cancer. 2017 Sep;82:115-127.

lamaroon A, Pattanaporn K, Pongsiriwet S, Wanachantararak S, Prapayasatok S, Jittidecharaks S, Chitapanarux I, Lorvidhaya V. Analysis of 587 cases of oral squamous cell carcinoma in nothern Thailand with a focus on young people. Int J Oral Maxillofac Surg. 2004 Jan;33(1):84-8.

INCA, Estimativa 2018: Incidência de câncer no Brasil. INCA; 2018; 130p. Instituto Nacional de Câncer José Alencar Gomes da Silva. Ministério da Saúde. Rio de Janeiro. Brasil. Acessado em junho de 2018.

lqbal AJ, McNeill E, Kapellos TS, Regan-Komito D, Norman S, Burd S, Smart N, Machemer DE, Stylianou E, McShane H, Channon KM, Chawla A, Greaves DR. Human CD68 promoter GFP transgenic mice allow analysis of monocyte to macrophage differentiation in vivo. Blood. 2014 Oct 9;124(15):e33-44.

Johnson KE, Wilgus TA. Vascular endotelial growth fator and angiogenesis in the regulation of cutaneous wound repair. Adv Wound Care (New Rochelle). 2014 Oct 1; 3(10): 647-661.

Jung S, Sielker S, Purcz N, Sproll C, Acil Yahva, Kleinheinz J. Analysis of angiogenic markers in oral squamous cell carcinoma-gene and protein expression. Head Face Med. 2015; 11: 19.

Kaminagakura E, Caris A, Coutinho-Camillo C, Soares FA, Takahama-Júnior A, Kowalski LP. Protein expression of CYP1A1, CYP1B1, ALDH1A1 and ALDH2 in young patients with oral squamous cell carcinoma. Int J Oral Maxillofac. 2016 Jun;45(6):706-12.

Kaminagakura E, Werneck da Cunha. Soares FA, Nishimoto IN, Kowalski LP. CCND1 amplification and protein overexpression in oral squamous cell carcinoma of young patients. Head Neck. 2011 Oct;33(10):1413-9. 
Kuriakose M, Sankaranarayanan M, Nair MK, Cherian T, Sugar AW, Scully C, Prime SS. Comparison of oral squamous cell carcinoma in younger and older patients in India. Eur $\mathrm{J}$ Cancer B Oral Oncol. 1992 Oct;28B (2):113-20.

Lima SC, Rizo VH, Silva-Sousa YT, Almeida LY, Almeida OP, León JE. Immunohistochemical evaluation of angiogenesis and tryptase-positive mast cell infiltration in periapical lesions. J Endod. 2011 Dec;37(12):1642-6.

Liu SY, Chang LC, Pan LF, Hung YJ, Lee CH, Shieh YS. Clinicpathologic significance of tumor cell-lined vessel and microenvironment in oral squamous cell carcinoma. Oral Oncol. 2008 Mar;44(3):277-85.

Lippitz BE. Cytokine patterns in patients with cancer: a systematic review. Lancet Oncol. 2013 May;14(6):e218-28.

Lu CF, Huang CS, Tihu JW, Chiang CP. Infiltrating macrophage count: a significant for the progression and prognosis of oral cell carcinomas in Taiwan. Head Neck. 2010 Jan;32(1):1825.

Lucio PS, Ribeiro DC, Aguiar MC, Alves PM, Nonaka CF, Godoy GP. Tumor-associated macrophages (TAMs): clinical-pathological parameters in squamous cell carcinoma of the lower lip. Braz Oral Res. 2016 Aug 22;30(1):e95.

Llewellyn CD, Linklater K, Bell J, Johnson NW, Warnakulasuriya S. An analysis of risk factors for oral cancer in young people: a case-control study. Oral Oncol. 2004 Mar;40(3):304-13.

Ma Q, Dieterich LC, Detmar M. Multiple roles of lymphatic vessels in tumor progression. Curr Opin Immunol. 2018 Aug;53:7-12.

Mackenzie J, Ah-See K, Thakker N, Sloan P, Maran AG, Birch J, Macfarlane GJ. Increasing incidence of oral cancer amongst young persons: what is the aetiology? Oral Oncol. 2000 Jul;36(4):387-9.

Mallet Y,Avalos N, Le Ridant AM, Gangloff P, Moriniere S, Rame JP, Poissonnet G, Makeieff M, Cosmidis A, Babin E, Barry B, Fournier C. Head and neck cancer in young people: a series of 52 SCCs of the oral tongue in patients aged 35 years or less. Acta Otolaryngol. 2009 Dec;129(12):1503-8.

Mancino A, Lawrence T. Nuclear fator-kappaB and tumor-associated macrophages. Clin Cancer Res. 2010 Feb 1;16(3):784-9.

Maniecki MB, Etzerodt A, Moestrup SK, Møller HJ, Graversen JH. Comparative assessment of the recognition of domains-specific CD163 monoclonal antibodies in human monocytes explains wide discrepancy in reported levels of cellular surface CD163 expression. Immunobiology. 2011 Aug;216(8):882-90.

Mantovani A, Marchesi F, Malesci A, Laghi L, Allavena P. Tumor-associated macrophages as treatment targets in oncology. Nat Rev Clin Oncol. 2017 Jul;14(7):399-416.

Manuel S, Raghavan SK, Pandey M, Sebastian P. Survival in patients under 45 years with squamous cell carcinoma of the oral tongue. Int J Oral Maxillofac Surg. 2003 Apr;32(2):16773. 
Marcus B, Arenberg D, Lee J, Kleer C, Chepeha DB, Schmalbach CE, Islam M, Paul S, Pan Q, Hanash S, Kuick R, Merajver SD, Teknos TN. Prognostic factors in oral cavity and oropharyngeal squamous cell carcinoma. Cancer. 2004 Dec 15;101(12):2779-87.

Mărgăritescu C, Pirici D, Stîngă A, Simionescu C, Raica M, Mogoantă L, Stepan A, Ribatti D. VEGF expression and angiogenesis in oral squamous in oral squamous cell carcinoma: na immunohistochemical and morphometric study. Clin Exp Med. 2010 Dec;10(4):209-14.

Mărgăritescu C, Simionescu C, Mogoantă L, Badea P, Pirici D, Stepan A, Ciurea R.Endoglin (CD105) and microvessel density in oral squamous cell carcinoma. Rom J Morphol Embryol. 2008;49(3):321-6.

Maturana-Ramírez A, Espinoza I, Reyes M, Aitken JP, Aguayo F, Hartel S, Rojas-Alcayaga G. Higher blood vessel density in comparison to he lymphatic vessels in oral squamous cell carcinoma. Int J Clin Exp Pathol. 2015 Oct 1;8(10):13677-86.

Matsuoka Y, Yoshida R, Nakavama H, Nagata M, Hirosue A, Tanaka T, Kawahara K, Nagakawa Y, Sakata J, Arita H, Hiraki A, Shinohara M. The tumour stromal features are associated with resistance to 5-FU-based chemoradiotherapy and a poor prognosis in patients with oral squamous cell carcinoma. APMIS. 2015 Mar;123(3):205-14.

Medrek C, Pontén F, Jirström K, Leandersson K. The presence of tumor associated macrophages in tumor stroma as a prognostic marker for breast câncer patients. BMC Cancer. 2012 Jul 23;12:306.

Mei J, Xiao Z, Guo C, Pu Q, Ma L, Liu C, Lin F, Liao H, You Z, Liu L. Prognostic impact of tumor-associated macrophage infiltration in non-small cell lung câncer: A systematic review and meta-analysis. Oncotarget. 2016 Jun 7;7(23):34217-28.

Miranda Galvis M, Santos-Silva AR, Freitas Jardim J, Paiva Fonseca F, Lopes MA, de Almeida OP, Lópes Pinto CA, Kaminagakura E, Sawazaki-Calone I, Speight PM, Kowalski LP. Different patterns of expression of cell cycle control and local invasion-related proteins in oral squamous cell carcinoma affecting young patients. J Oral Pathol Med. 2018 Jan;47(1):32-39.

Miranda Galvis M, Freitas Jardim J, Kaminagakura E, Santos-Silva AR, Paiva Fonseca F, Paes Almeida O, Ajudarte Lopes M, Lópes Pinto C, Kowalski LP. Expression of cell cycle proteins to HPV status in oral squamous cell carcinoma affecting young patients: a pilot study. Oral Surg Oral Med Oral Pathol Oral Radiol. 2018 Apr;125(4):317-325.

Moura JMBO, Câmara ACSM, Nonaka CFW, Pinto LP, Souza LB. Immunohistochemical comparative analysis of lymphatic vessel density and VEGFC expression in squamous cell carcinomas of the tongue between young and old patients. Pathol Res Pract. 2016 Dec;212(12):1095-1101.

Mori K, Hiroi M, Shimada J, Ohmori Y. Infiltration of $\mathrm{m} 2$ tumor-associated macrophages in oral squamous cell carcinoma correlates with tumor malignancy. Cancers (Basel). 2011 Sep 28;3(4):3726-39.

Moro JS, Maroneze MC, Ardenghi TM, Barin LM, Danesi. Oral and orophayngeal câncer: epidemiology and survival analysis. Einstein (Sao Paulo). 2018; 16(2): eAO4248.

Neville BW, Day TA. Oral câncer and precancerous lesions. CA Cancer J Clin. 2002 JulAug;52(4):195-215. 
Ni YH, Ding L, Huang XF, Dong YC, Hu QG, Hou YY. Microlocalization of CD68+ tumor associated in tumor stroma correlated with poor clinical outcomes in oral squamous cell carcinoma patients. Tumour Biol. 2015 Jul;36(7):5291-8.

Oliveira-Neto HH, Gleber-Netto FO, de Souza SF, França CM, Aguiar MC, Silva TA, Batista AC. A comparative study of microvessel density in squamous cell carcinoma of the oral cavity and lip. Oral Surg Oral Med Oral Pathol Oral Radiol. 2012 Mar; 113(3):391-8.

Patel SC, Carpenter WR, Tyree S, Couch ME, Weissler M, Hackman T, Hayes DN, Shores $\mathrm{C}$, Chera BS. Increasing incidence of oral tongue squamous cell carcinoma in Young White woman, age 18 to 44 years. J Clin Oncol. 2011. Apr 10;29(11): 1488-94.

Pei BX, Sun BS, Zhang ZF, Wang AL, Ren P. Intersticial tumor-associated macrophages combined with tumor-derived colony-stimulating fator-1 and interleukin-6, a novel biomarker in non-small cell lung câncer. J Thorac Cardiovasc Surg. 2014 Oct;148(4):1208-1216

Perisanidis C, Sulzbacher I, Mittlböck M, Mitchell D, Czembirek C, Seemann R, Ewers R, Schopper C, Selzer E. Survival of patients with pathologic TON+ oral and oropharyngeal câncer after neoadjuvant therapy and surgery: the minority report. Oral Surg Oral Med Oral Pathol Oral Radiol. 2013 Mar;115(3):293-8.

Pettersen JS, Fuentes-Duculan J, Suárez-Fariñas M, Pierson KC, Pitts-Kiefer A, Fan L, Belkin DA, Wang CQ, Bhuvanendran S, Johnson-Huang LM, Bluth MJ, Krueger JG, Lowes MA, Carucci JA. Tumor-associated macrophages in the cutaneous SCC microenvironment are heterogeneously activated. J Invest Dermatol. 2011 Jun;131(6):1322-30.

Petruzzi MNM, Cherubini K, Salum FG, Figueiredo MAZ. Role of tumour-associated macrophages in oral squamous cells carcinoma progression: an update on current knowledge. Diagn Pathol. 2017; 12: 32.

Phelouzat MA, Seelentag W, Laforge T, Quadri RA, Proust JJ. Excessive apoptosis of mature $T$ lymphocytes is a characteristic feature of human immunossenescence. Mech Ageing Dev. 1996 Jul 5;88(1-2):25-38.

Pusztaszeri MP, Seelentag W, Bosman FT. Immunohistochemical expression of endothelial markers CD31, CD34, von Willebrand factor, and Fli-1 in normal human tissues. J Histochem Cytochem. 2006 Apr;54(4):385-95.

Raica M, Cimpean AM, Ribatti D. The role of podoplanin in tumor progression and metastasis. Anticancer Res. 2008 Sep-Oct;28(5B):2997-3006.

Ran S, Montgomery KE. Macrophages-mediated lymphangiogenesis: the emerging role of macrophages as lymphatc endotelial progenitors. Cancers (Basel). 2012 Sep;4(3):618-57.

Rapidis AD, Gullane P, Langdon JD, Lefebvre JL, Scully C, Shah JP. Major advances in the knowledge and understanding of the epidemiology, aetiopathogenesis, diagnosis, management and prognosis of oral cancer. Oral Oncol. 2009 Apr-May;45(4-5):299-300.

Riabov V, Gudima A, Wang N, Mickley A, Orekhov A, Kzhyshkowska J. Role of tumor associated macrophages in tumor angiogenesis and lymphagiogenesis. Front Physiol. 2014; 5: 75. 
Ribeiro AC, Silva AR, Simonato LE, Salzedas LM, Sundefeld ML, Soubhia AM. Clinical and histopathological analysis of oral squamous cell carcinoma in young people: a descriptive study in Brazilians. Br J Oral Maxillofac Surg. 2009 Mar;47(2):95-8.

Rikardsen OG, Bjerkli IH, Uhlin-Hansen L, Hadler-Olsen E, Steigen SE. Clinicopathological characteristics of oral squamous cell carcinoma in Northern Norway: a retrospective study. BMC Oral Health. 2014; 14: 103.

Rijke JM, Schouten LJ, Schouten HC, Jager JJ, Koppejan AG, van den Brandt PA. Agespecific diferences in the treatment of câncer patients aged 50 years and older in the province of Limburg. Ann Oncol. The Netherlands. Ann Oncol. 1996 Sep;7(7):677-85.

Ruffell B, Affara NI, Coussens LM. Differential macrophage programming in the tumor microenvironment. Trends Immunol. 2012 Mar;33(3):119-26.

Sánchez-Romero C, Bologna-Molina R, Mosqueda-Taylor A, de Almeida OP. Immunohistochemical expression of podoplanin (D2-40), lymphangiogenesis, and neoangiogenesis in tooth germ, ameloblastomas, and ameloblastic carcinomas. J Oral Pathol Med. 2017 Sep;46(8):618-624.

Scully C, Bagan J. Oral squamous cell carcinoma overview. Oral Oncol. 2009 Apr-May;45(45):301-8.

Sebastían C, Espia M, Serra M, Celada A, Lloberas J. MacrophAging: A cellular and molecular review. Immunobiology. 2005;210(2-4):121-6.

Sgaramella N, Lindell Jonsson E, Boldrup L, Califano L, Coates PJ, Tartaro G, Lo Muzio L, Fåhraeus R, Colella G, Dell'Aversana Orabona G, Loljung L, Santagata M, Rossiello R, Wilms T, Danielsson K, Laurell G, Nylander K. High expression of podoplanin in squamous cell carcinoma of the tongue occurs predominantly in patients' $\leq 40$ years but does not correlate with tumour spread. J Pathol Clin Res. 2015 Oct 9;2(1):3-8.

Shahsavari F, Farhadi S, Sadri D, Sedehi M. Evaluation of microvascularity by CD34 expression in esophagus and oral squamous cell carcinoma. J Contemp Dent Pract. 2015 Jun $1 ; 16(6): 458-62$.

Shao Z, Zhang WF, Chen XM, Shang ZJ. Expression of EphA2 and VEGF in squamous cell carcinoma of the tongue: correlation with angiogenesis and clinical outcome. Oral Oncol. 2008 Dec;44(12):1110-7.

Shivamallappa SM, Venkatraman NT, Shreedhar B, Mohanty L, Shenoy S. Role of angiogenesis in oral squamous cell carcinoma development and metastasis: an immunohistochemical study. Int J Oral Sci. 2011 Oct;3(4):216-24.

Silverman S Jr. Early diagnosis of oral câncer. Cancer. 1988 Oct 15;62(8 Suppl):1796-9.

Siriwardena BS, Tilakaratne A, Amaratunga EA, Tilakaratne WM. Demographic, aetiological and survival diferences of oral squamous cell carcinoma in the young and the old in Sri Lanka. Oral Oncol. 2006 Sep;42(8):831-6.

Siriwardena BS, Tilakaratne A, Amaratunga EA, Udagama MN, Ogawa I, Kudo Y, Takata T, Tilakaratne WM. Analysis of histopathological diferences of oral squamous cell carcinoma in Young and old patients in Sri Lanka. J Oral Pathol Med. 2007 Jul; 36(6): 357-62. 
Sun Q, Fang Q, Guo S. A comparison of oral squamous cell carcinoma between young and old patients in a single medical center in China. Int J Clin Exp Med. 2015; 8(8): 1241812423.

Syedmukith R, Ahmedmujib BR, Bastian TS. Oral Squamous Cell Carcinoma in Elderly vs Young Patients: A Comparative Analysis using STNMP Staging System. Oral and Maxillofacial Pathology Journal, July-December 2014; 5(2):471-475.

Takagi S, Inenaga R, Oya R, Nakamura S, Ikemura K. Blood vessel density correlates with the effects of target intra-arterial carboplatin infusion with concurrent radiotherapy for squamous cell carcinomas of the oral cavity and oropharynx. $\mathrm{Br} \mathrm{J}$ Cancer. $2006 \mathrm{Jun} 5$; 94(11): $1580-5$

Tipoe GL, Jin Y, White FH. The relationship between vascularity and cell proliferation in human normal and pathological lesion of the oral cheek epithelium. Eur $\mathrm{J}$ Cancer B Oral Oncol. 1996 Jan;32B (1):24-31.

Troeltzch M, Knösel T, Eichinger C, Probst F, Troeltzch M, Woodlock T, Mast G, Ehrenfeld M, Otto S. Clinicopathologic features of oral squamous cell carcinoma do they vary in different age-groups? J Oral Maxillofac Surg. 2014 Jul; 72(7): 1291-300.

Udeabor SE, Adisa AO, Orlowska A, Sader RA, Ghanaati S. Tumor-associated macrophages, angiogenesis, and tumor cell migration in oral squamous cell carcinoma. Ann Afr Med. 2017 Oct-Dec;16(4):181-185.

Utrera-Barillas D, Castro-Manrreza M, Castellanos E, Gutiérrez-Rodríguez M, Arciniega-Ruíz de Esparza O, García-Cebada J, Velazquez JR, Flores-Reséndiz D, Hernández-Hernández $D$, Benítez-Bribiesca $L$. The role of macrophages and mast cells in lymphangiogenesis and angiogenesis in cervical carcinogenesis. Exp Mol Pathol. 2010 Oct;89(2):190-6.

Veness MJ, Morgan GJ, Sathiyaseelan Y, Gebski V. Anterior tongue cancer: age is not a predictor of outcome and should not alter treatment. ANZ J Surg. 2003 Nov;73(11):899-904.

Yang J, Li X, Liu X, Liu Y. The role of tumor-associated macrophages in breast carcinoma invasion and metastasis. Int J Clin Exp Pathol. 2015 Jun 1;8(6):6656-64.

Yuan X, Zhang J, Li D, Mao Y, Mo F, Du W, Ma X. Prognostic significance of tumorassociated macrophages in ovarian cancer: A meta-analysis. Gynecol Oncol. 2017 Oct;147(1):181-187.

Zhang $M$, He Y, Sun X, Li Q, Wang W, Zhao A, Di W. A high M2/M2 ratio of tumorassociated macrophages with extensed survival in ovarian câncer patients. J Ovarian Res. 2014 Feb 8;7: 19.

Zhang Y, Cheng S, Zhang M, Zhen L, Pang D, Zhang Q, Li Z. High-infiltration of tumorassociated macrophages predicts unfavorable clinical outcome for node-negative breast câncer. PLoS One. 2013 Sep 30;8(9): e76147.

Zhao Y, Adjei AA. Targeting Angiogenesis in Cancer Therapy: Moving Beyond Vascular Endothelial Growth Factor. Oncologist. 2015 Jun; 20(6): 660-73. 
Zhao X, Qu J, Sun Y, Wang J, Liu X, Wang F, Zhang H, Wang W, Ma X, Gao X, Zhang S. Prognostic significance of tumor-associated macrophages in breast cancer: a meta-analysis of the literature. Oncotarget. 2017 May 2;8(18):30576-30586.

Zhang YY, Wang DC, Su JZ, Jia LF, Peng X, Yu GY. Clinicopathological characteristics and outcomes of squamous cell carcinoma of the tongue in different age groups. Head Neck. 2017 Nov;39(11):2276-2282.

Zhu Q, Wu X, Wu Y, Wang X. Interaction between Treg cells and tumor-associated macrophages in the microenvironment of epitelial ovarian câncer. Oncol Rep. 2016 Dec;36(6):3472-3478.

Yamagata Y, Tomioka H, Sakamoto K, Sato K, Harada H, Ikeda T, Kayamori K. CD163Positive macrophages within the tumor stroma are associated with lymphangiogenesis and lymph node metastasis in oral squamous cell carcinoma. J Oral Maxillofac Surg. 2017 Oct;75(10):2144-2153.

Wang S, Sun M, Gu C, Wang X, Chen D, Zhao E, Jiao X, Zheng J. Expression of CD163, interleukin-10, and interferon-gamma in oral squamous cell carcinoma: mutual relationship and prognostic implications. Eur J Oral Sci. 2014 Jun;122(3):202-9.

Warnakulasuriya S. Living with oral cancer: epidemiology with particular reference to prevalence and life-style changes that influence survival. Oral Oncol. 2010 Jun;46(6):407-10.

Warnakulasuriya S. Global epidemiology of oral and oropharyngeal cancer. Oral Oncol. 2009 Apr-May;45(4-5):309-16.

Weber M, Iliopoulos C, Moebius P, Büttner-Herold M, Amann K, Ries J, Preidl R, Neukam FW, Wehrhan F. Prognostic significance of macrophage polarization in early stage oral squamous cell carcinomas. Oral Oncol. 2016 Jan;52:75-84.

Wei W, Hu-Jie C. Association of the infiltration of tumor-associated macrophages, expression of Smad7 protein and prognosis in oral squamous cell carcinoma. Arch Oral Biol. 2018 Nov; 95:22-29.

Weidner N. Tumor angiogenesis: review of current applications in tumor prognostication. Semin Diagn Pathol. 1993 Nov;10(4):302-13.

Weidner N, Semple JP, Welch WR, Folkman J. Tumor angiogenesis and metastasis correlation in invasive breast carcinoma. N Engl J Med. 1991 Jan 3;324(1):1-8.

Wehrhan F, Büttner-Herold M, Hyckel P, Moebius P, Preidl R, Distel L, Ries J, Amann K, Schmitt C, Neukam FW, Weber M. Increased malignancy of oral squamous cell carcinomas (oscc) is associated with macrophage polarization in regional lymph nodes - an immunhistochemical study. BMC Cancer. 2014 Jul 21;14:522.

Weyand CM, Goronzy JJ. Aging of the imune system. Mechanisms and therapeutic targets. Ann Am Thorac Soc. 2016 Dec;13 Suppl 5:S422-S428.

Wu H, Xu JB, He YL, Peng JJ, Zhang XH, Chen CQ, Li W, Cai SR. Tumor-associated macrophages promote angiogenesis and lymphangiogenesis of gastric câncer. J Surg Oncol. 2012 Sep 15; 106(4): 462-8. 


\section{APÊNDICE}




\section{APÊNDICE}

\section{APÊNDICE 1: Aprovação do Comitê de Ética em Pesquisa}

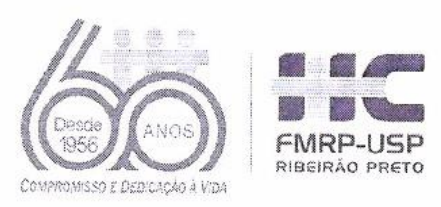

Ribeirão Preto, 09 de fevereiro de 2017

Oficio $\mathrm{n}^{\circ} 383 / 2017$

CEP/MGV

Prezada Senhora,

O trabalho intitulado "ESTUDO CLINICOPATOLÓGICO, IMUNOISTOQUÍMICO, HIBRIDIZAÇÃO IN SITU E GENÉTICA MOLECULAR EM CARCINOMAS ESPINOCELULARES DA REGIÃo DE CABEÇA E PESCOÇo" versão 2, de 06/12/2016, foi analisado pelo Comitê de Ética em Pesquisa, em sua $443^{a}$ Reuniāo Ordinária realizada em 06/02/2017 e enquadrado na categoria: APROVADO, bem como a solicitação de dispensa do Termo de Consentimento Livre e Esclarecido, de acordo com o Processo HCRP n $13607 / 2016$.

Este Comitê segue integralmente a Conferência Internacional de Harmonização de Boas Práticas Clínicas (IGH-GCP), bem como a Resolução $n^{\circ} 466 / 12$ CNS/MS.

Lembramos que devem ser apresentados a este CEP, o Relatório Parcial e o Relatório Final da pesquisa.

Atenciosamente.

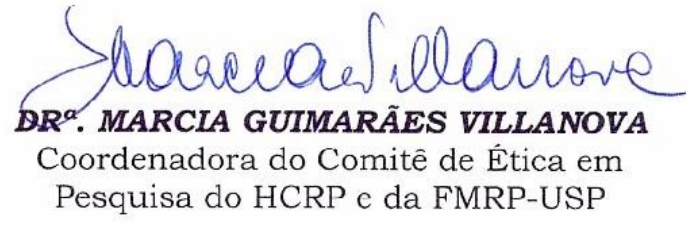

Ilustrissima Senhora

JÉSSICA SANTOS

Depto. de Patologia e Medicina Legal

HOSPITAL DAS CLÍNICAS DA FACULDADE DE MEDICINA DE RIBEIRÄO PRETO DA UNIVERSIDADE DE SÄO PAULO Campus Universitário - Monte Alegre 14048-900 Ribeirão Preto SP 